\title{
LEDGF gene silencing impairs the tumorigenicity of prostate cancer DU145 cells by abating the expression of Hsp27 and activation of the Akt/ERK signaling pathway
}

\author{
B Bhargavan ${ }^{1}$, N Fatma ${ }^{1}$, B Chhunchha ${ }^{1}$, V Singh ${ }^{1}$, E Kubo $^{2}$ and DP Singh ${ }^{\star, 1}$
}

Lens epithelium-derived growth factor (LEDGF) maintains survival pathways by augmenting the transcription of stress-response genes such as small heat-shock protein 27. Recently, aberrant expression of LEDGF was found in prostate cancer (PC). Herein, we showed that LEDGF overexpression upregulated Hsp27 in PC cells, DU145, PC-3 and LNCaP and promoted antiapoptotic pathways in PCs. We found that these cells had higher abundance of Hsp27, which was correlated with the levels of LEDGF expression. Transactivation assay in DU145 cells revealed that transactivation of Hsp27 was related to the magnitude of LEDGF expression. Silencing of LEDGF in DU145 cells abrogated Hsp27 expression and inhibited stimulated cell proliferation, invasiveness and migration. These cells were arrested in S and G2 phase, and failed to accumulate cyclin B1, and showed increased apoptosis. Furthermore, LEDGF-depleted DU145 cells displayed elevated Bax and cleaved caspase 9 expression and reduced levels of $\mathrm{Bc} / 2, \mathrm{Bcl}-\mathrm{xL}$. The activated survival pathway(s), ERK1/2 and Akt, were selectively decreased in these cells, which characteristically have lower tumorigenicity. Conversely, the depleted cells, when re-overexpressed with LEDGF or Hsp27, regained tumorigenic properties. Collectively, results reveal the involvement of LEDGF-mediated elevated expression of Hsp27dependent survival pathway(s) in PC. Our findings suggest new lines of investigation aimed at developing therapies by targeting LEDGF or its aberrant expression-associated stimulated antiapoptotic pathway(s).

Cell Death and Disease (2012) 3, e316; doi:10.1038/cddis.2012.57; published online 31 May 2012

Subject Category: Cancer

A multi-domain flexible nuclear protein, lens epitheliumderived growth factor (LEDGF), exercises a variety of functions involving cellular abnormalities by interacting with DNA/protein. ${ }^{1-5}$ LEDGF was originally identified as a transcriptional protein that binds to chromatin/DNA ${ }^{1,6}$ mapped to chromosome 9p22.3 genetic locus. ${ }^{2,7}$ Recently, LEDGF has been shown to interact with multiple proteins such as Mycinteracting protein $\mathrm{JPO}^{8}$ and mixed-lineage leukemia/menin complex, ${ }^{9}$ a domesticated transposase pogo transposable element-derived protein with zinc finger ${ }^{10}$ and Cdc7-activator of S-phase kinase (ASK). ${ }^{11}$ Furthermore, its helix-turnhelix-like motifs (aa, 421-442 and aa, 471-492) bind to heat-shock element (nGAAn), and N-terminal LEDGF interacts with stress-response elements (nA/TGGGGA/Tn), thereby regulating transcription of small heat-shock proteins (Hsps) such as $\alpha \mathrm{B}$-crystallin and Hsp27 $7^{1,12,13}$ and enhancing cell survival. ${ }^{1,14,15}$

Recently, aberrant expression of LEDGF was found to be involved in development of various types of cancers including subcutaneous angiogenesis and lymphangiogenesis of ovarian carcinoma tumors. ${ }^{16,17}$ More recently, elevated expression of LEDGF was reported in $61 \%$ of prostate tumors. ${ }^{18}$
Moreover, stress-inducible LEDGF provides cell survival by upregulating Hsp27.,19 Hsp27 belongs to the family of 'survival proteins' and its involvement has been found in a number of cell death pathways induced by cellular and environmental stresses. ${ }^{20}$ We posit that LEDGF-mediated overexpression of $\mathrm{Hsp} 27$ protein may alter the crucial balance between cell proliferation and cell death, which in turn may lead to cell transformation. Hsp27 can modulate cell proliferation by interacting with the Akt pathway, which has a pivotal role in the survival of many types of cancer cells. ${ }^{21-25}$ As LEDGF is an enhancer of Hsp27, and enhanced expression of Hsp27 is known to be a causative factor in prostate cancer (PC) progression and invasiveness, ${ }^{26}$ we hypothesize that LEDGF-induced tumorigenicity may be selectively associated with upregulation of Hsp27-mediated antiapoptotic signaling in PC cells. ${ }^{27,28}$

During carcinogenesis, a large majority of signaling molecules are affected, and their downstream effectors are generally transcription factors. The smaller numbers of these transcription factors may be an ideal target for treating/ postponing cancer formation. ${ }^{29}$ Thus, we think that LEDGF should be a potential and promising target for development of

\footnotetext{
${ }^{1}$ Department of Ophthalmology and Visual Sciences, University of Nebraska Medical Center, Omaha, NE 68198-5840, USA and ${ }^{2}$ Department of Ophthalmology, University of Kanazawa, Ishikawa, Japan

${ }^{*}$ Corresponding author: DP Singh, Department of Ophthalmology and Visual Sciences, University of Nebraska Medical Center, Omaha, NE 68198-5840, USA. Tel: 402559 8805; Fax: 402559 8808; E-mail: dpsingh@unmc.edu

Keywords: LEDGF; transcription; Hsp27; DU145; PWR-1E; apoptosis

Abbreviations: LEDGF, lens epithelium-derived growth factor; PC, prostate cancer

Received 15.2.12; revised 16.4.12; accepted 23.4.12; Edited by A Stephanou
} 
transcription-based therapeutics. ${ }^{30}$ The RNA interference technology has been shown to be a successful and effective way of inhibiting the synthesis of specific protein. ${ }^{31}$ In the current study, we found that expression of LEDGF dramatically elevated in PC cells, DU145, PC-3 and LNCaP. Additionally, we showed that if LEDGF was overexpressed in normal prostate cells, PWR-1E led to transformation, and these cells showed characteristics of cancer cell, DU145. Notably, DU145 cells aberrantly expressing LEDGF or overexpressed with LEDGF displayed enhanced and aggressive characteristic features of tumorigenicity (Figures 8 and 9). In this work, we provide evidence that knocking down of LEDGF in DU145 by LEDGF-targeted small interfering RNA (siRNA) reduced tumorigenicity, and reduced tumorigenicity was related to reduced expression of $\mathrm{Hsp} 27$ and attenuation of Hsp27-mediated survival pathways(s). As a whole, our findings not only offer new perspectives in the modulation of cellular events by LEDGF but also suggest a novel therapeutic target for cancer treatment.

\section{Results} Aberrant expression of LEDGF in human prostate
carcinoma cells DU145, PC-3 and LNCaP was associated
with increased expression of its downstream target Hsp27. Using an androgen-independent PC cell line DU145 we studied whether increased expression of LEDGF was associated with increased expression of Hsp27 and compared with normal prostate epithelial cell line PWR-1E. Analysis of LEDGF expression by real-time PCR and western blot analyses showed that the DU145 cells harbored significantly elevated expression of LEDGF protein in nucleus (Figure 1a, lane 2 versus 4) and mRNA (Figure 1b, gray bar) compared with normal cells (PWR-1E). Interestingly, mRNA expression of LEDGF in DU145 cells was approximately seven-fold higher than in normal cells (Figure 1b). Next, we tested whether levels of Hsp27 protein and mRNA were also increased in DU145 cells, as LEDGF is a regulator of Hsp27. Figure 1c (lane 2) and Figure 1d (gray bar) demonstrate that indeed, the levels of Hsp27 were elevated in DU145 cells.

Next, we examined whether the expression of LEDGF was elevated in other androgen-dependent human PC cell lines, PC-3 and LNCaP. As shown in the Figure 1e, these cell lines also harbored elevated LEDGF protein (Figure 1e, upper panel; lanes 2, 3 and 4). Observed increased levels of Hsp27 in these cell lines (Figure 1e, middle panel; lane 1 versus 2, 3 and 4) indicating a correlation between LEDGF expression and Hsp27. Furthermore, the expression levels of LEDGF and Hsp27 mRNA were also significantly higher in the PC cell lines (Figure 1f) as evidenced by real-time PCR. In the current study, we have chosen to perform experiments using normal cells PWR-1E and DU145.

\section{LEDGF overexpression enhanced the transactivation of Hsp27 promoter and increased the migration and invasiveness of DU145 cells. On the basis of our earlier work, ${ }^{1}$ we hypothesized that the increased expression of LEDGF may be one factor in the increased Hsp27 expres- sion in DU145 cells. To test this, we first confirmed}

localization pattern and integrity of ectopically expressed pEGFP-LEDGF in DU145. Figure 2A showed that the ectopically expressed pEGFP-LEDGF protein localized in nucleus. Next, we wished to examine DU145 containing elevated expression of LEDGF, whether these cells overexpressed with LEDGF display further increase in the expression of Hsp27 mRNA. DU145 cells were overexpressed with different concentrations $(250,500 \mathrm{ng}, 1$ and $2 \mu \mathrm{g}$ ) of pEGFP-LEDGF. Real-time PCR analysis revealed LEDGF concentration-dependent increased expression of LEDGF mRNA (Figure 2B, black bars) and Hsp 27 (Figure 2B, gray bars). The increases in Hsp27 mRNA appeared to be associated with the abundance of LEDGF, further supports LEDGF as a regulator of Hsp27.

To examine whether LEDGF transactivated Hsp27 promoter in DU145, cells were co-transfected with varying concentrations of pEGFP-LEDGF or pEGFP-vector and Hsp27-CAT (co-transfection and promoter activity) promoter. CAT values increased significantly with increasing concentration of the LEDGF constructs (Figure 2C), indicating that Hsp27 was transactivated by LEDGF.

To determine whether LEDGF overexpression in these cells was functionally involved in enhancing tumorigenicity, cells overexpressing LEDGF were subjected to migration and invasion assays. In the migration assay, confluent and quiescent monolayers of cells were wounded. Photographs were taken $24 \mathrm{~h}$ after wounding to observe changes in migration (Figure 2D), and the distance of cell migration to the wound area was measured (Figure 2D right panel). Cells overexpressing LEDGF were found to have greater migration potential (Figure 2D). Also, we observed aggressive invasive behavior in cells overexpressing LEDGF (Figures $8 \mathrm{C}$ and Db). Data analysis revealed that cells ectopically expressed with LEDGF showed $\sim 45 \%$ increase in invasive behavior in comparison with vector-transfected cells.

Knockdown of LEDGF in DU145 effectively downregulated its downstream target Hsp27. To examine the direct involvement of LEDGF in tumorigenesis, DU145 cells were transfected with siRNA specific to LEDGF (Si-LEDGF) or scrambled siRNA vectors (Si-Control). Stably selected transfectants were examined for LEDGF mRNA (Figure 3a) and protein (Figure $3 b$ ) by real-time PCR and western blot. The results indicated that cells stably transfected with siRNA LEDGF had significantly reduced expression of LEDGF. Next, we tested whether these cells displayed lower expression of Hsp27 by performing western analysis using anti-Hsp27 antibody. Data revealed that reduced expression of Hsp27 was associated with LEDGF expression level (Figure 3c). To rule out the down regulation of Hsp27 expression is specific to LEDGF depletion, and not due to nonspecific silencing effects of siRNA used against LEDGF, we reprobed the membrane with specific antibodies for other proteins such as Sp1, $\operatorname{Prdx6}$ and $\beta$-actin (Figure 3c). Densitometry of immunoblots disclosed no change in the expression pattern of Sp1 or Prdx6 or $\beta$-actin, suggesting that Si-LEDGF specifically depleted LEDGF. To examine further whether Si-LEDGF reduced promoter activity of Hsp27, we performed transactivation assay. We found that Si-LEDGF cells displayed reduced Hsp27 promoter activity 
a
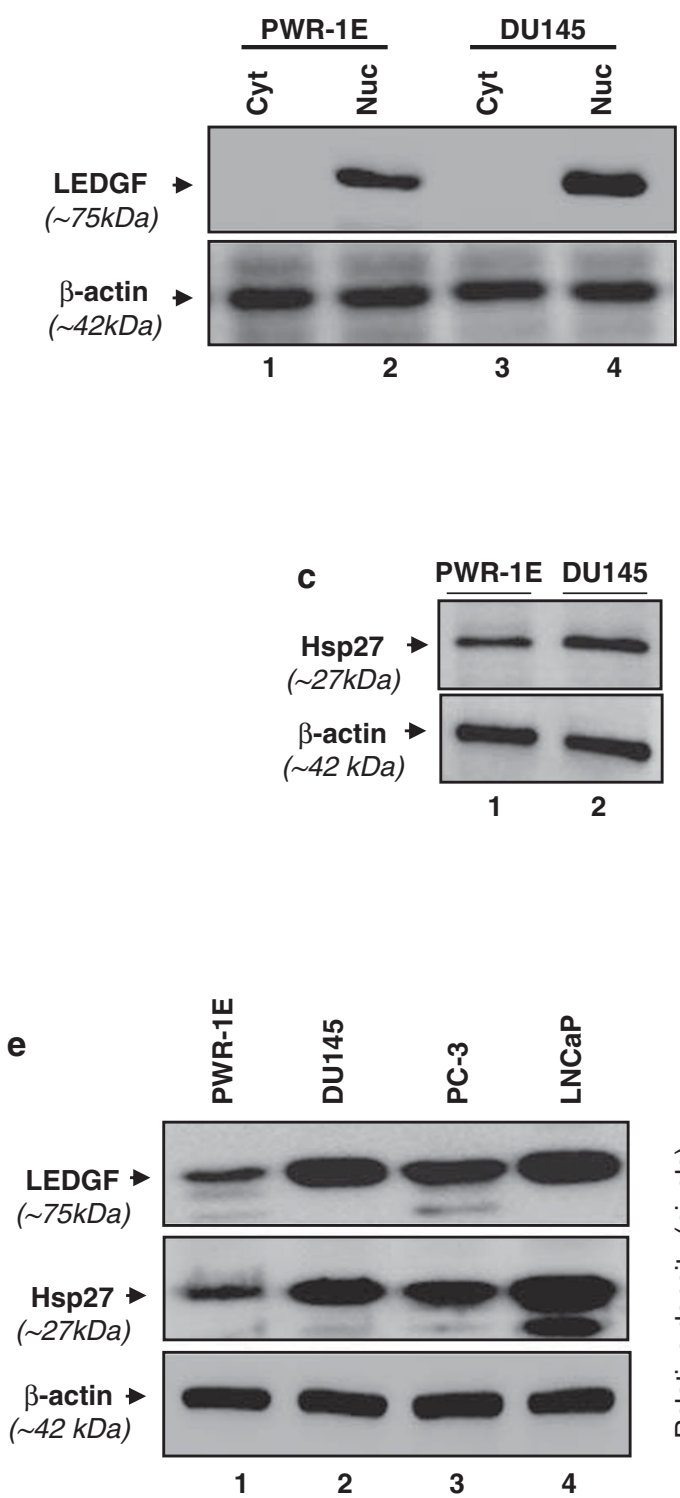
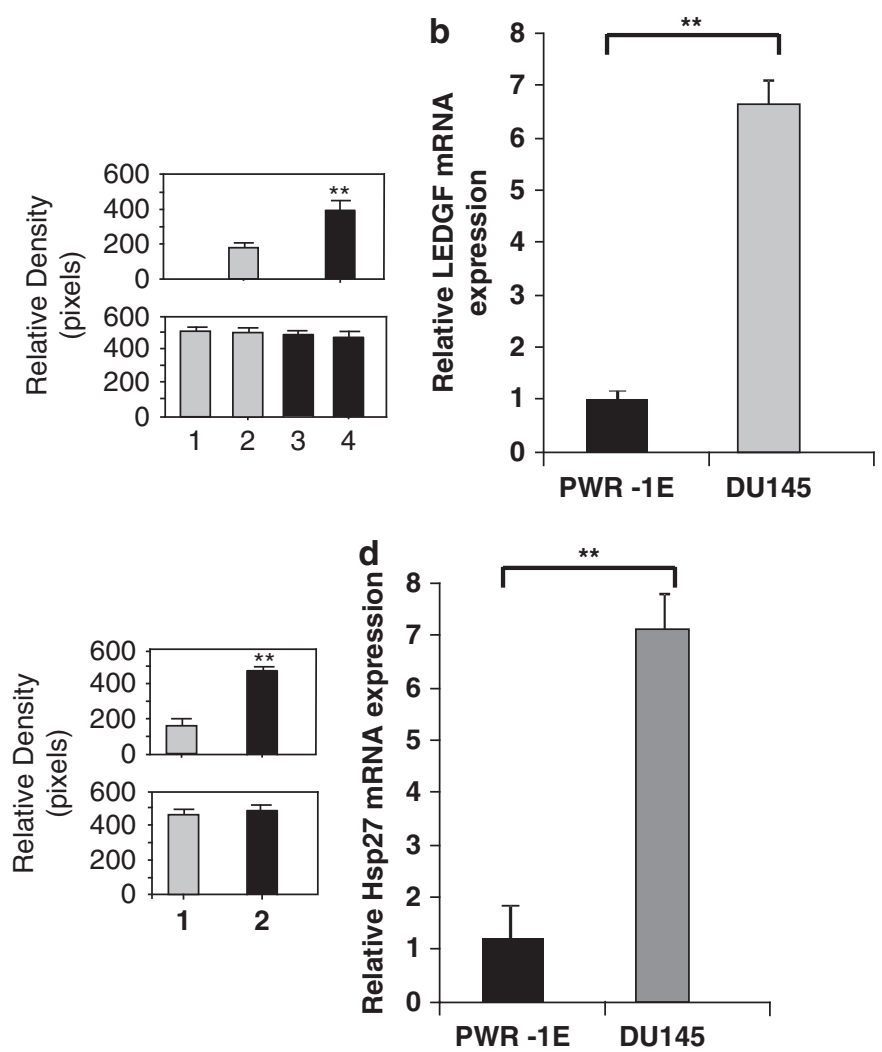

f

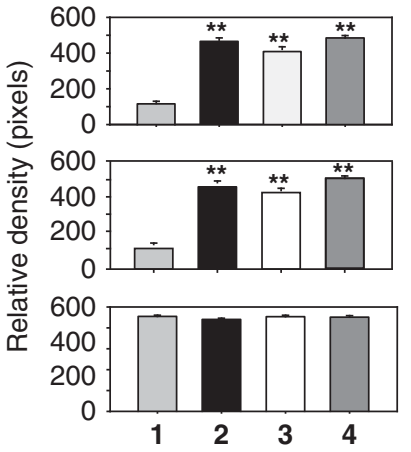

Figure 1 LEDGF, a transregulator of Hsp27, and Hsp27 were aberrantly co-expressed in DU145 cancer cells. (a) Western analysis of LEDGF protein isolated from normal prostate epithelial cells, PWR-1E (upper panel, lanes 1 and 2) and human prostate carcinoma cell line DU145 (upper panel, lanes 3 and 4). Nuclear or cytosolic extracts from confluent cells were prepared. Equal amounts of protein were resolved through SDS-PAGE and immunoblotted using anti-LEDGF. Lower panel shows membrane probed with $\beta$-actin antibody as loading/internal control. Each band of blot was quantified using densitometer shown as histogram (right). Images are representatives from three independent observations. (b) mRNA level expression of LEDGF was analyzed by real-time PCR. Total RNA was isolated from PWR-1E (black bar) or DU145 (gray bar) cells and reverse transcribed. CDNA was subjected to real-time PCR analysis with specific primers. Data represent the mean \pm S.D. from three independent experiments $\left({ }^{\star *} P<0.001\right)$. (c and d) Expression levels of Hsp27 protein (c) and mRNA (d) in PWR-1E and DU145 cells. Data represent the mean \pm S.D. from three independent experiments $\left({ }^{* *} P<0.001\right)$. (e and $\left.\mathbf{f}\right)$ Expression levels of LEDGF and Hsp27 protein $(\mathbf{e})$ and $\mathrm{mRNA}(\mathbf{f})$ in different prostate adenocarcinoma cell lines as indicated compared with normal prostate epithelium-derived cell line PWR-1E. Data represent the mean \pm S.D. from three independent experiments $\left({ }^{\star \star} P<0.001\right)$. Each band of blot was quantified using densitometer shown at the right of western blot images

compared with Si-Control cells (Figure 3d, open bar versus gray bar).

Furthermore, it is known that activated STAT3 upregulates Hsp27 and facilitate phosphorylation of Hsp27 at serine residue 78 and aberrant STAT3 signaling induces cell malignancies. We, therefore, next examined the level of STAT3 expression in LEDGF-depleted cells. We could observe a reduced level of total (Figure $3 e$, upper panel) and phosphorylated (Figure $3 e$, middle panel) forms of STAT3 protein. 
Knockdown of LEDGF in DU145 cells suppressed proliferation and survival. To determine whether Si-LEDGF attenuates the tumorigenic character of DU145 cells, we did proliferation/cell viability of stably transfected Si-LEDGF-DU145. On day 0 (baseline), Si-LEDGF cells or Si-Control cells were seeded at equal density, and cell
A
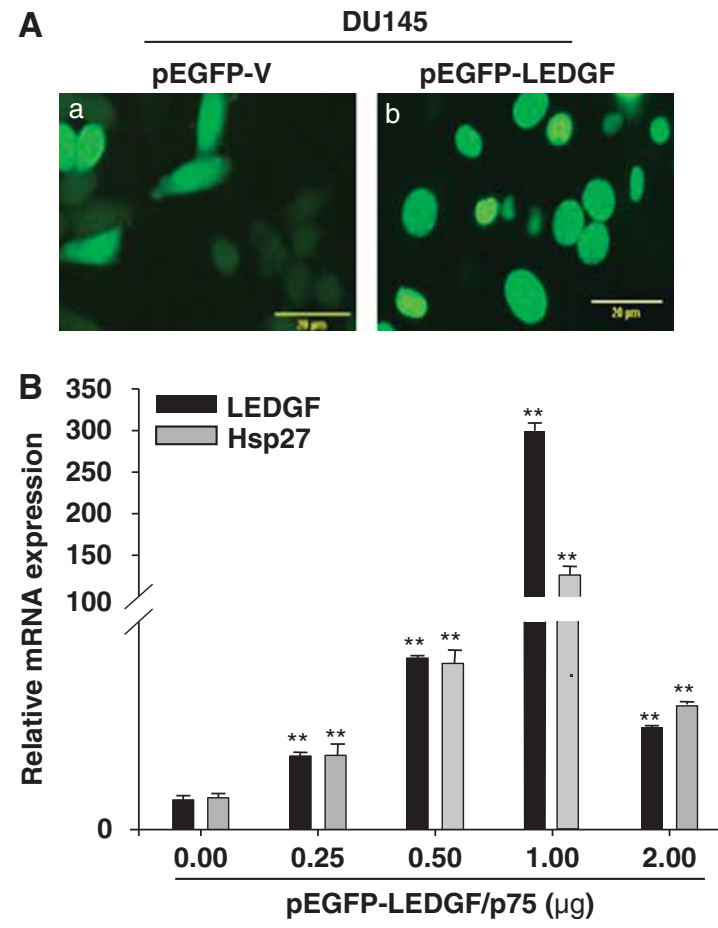

C

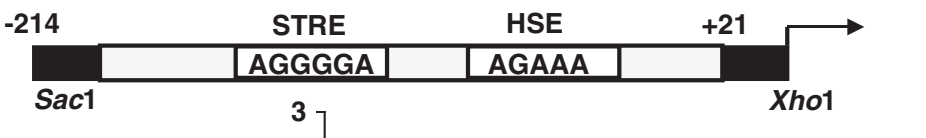

D PEGFP-V
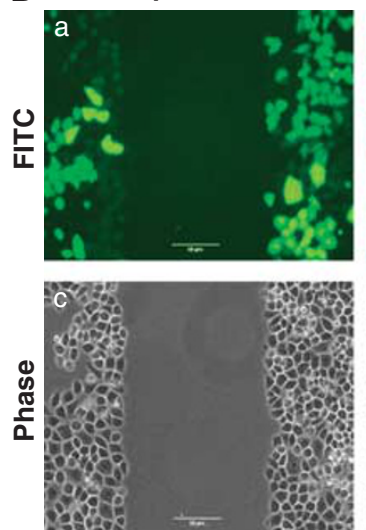

PEGFP-LEDGF
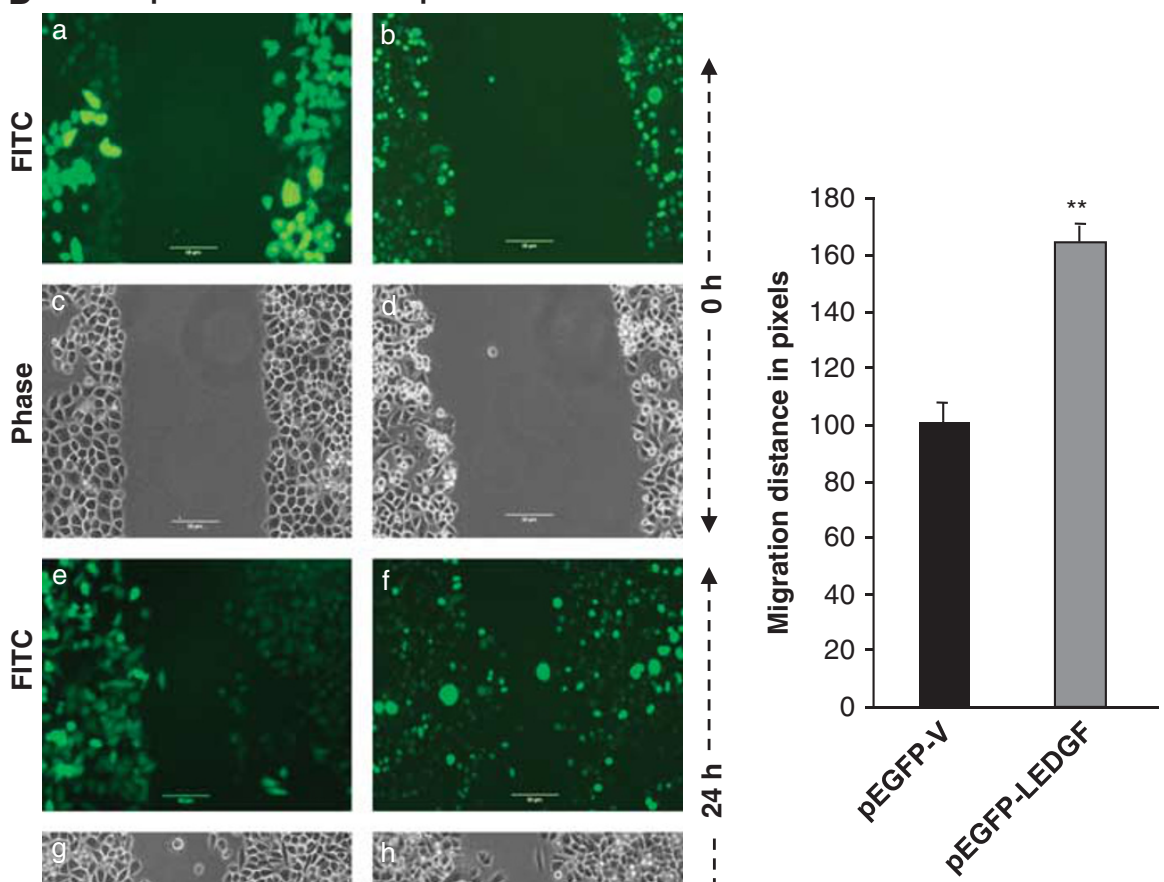
proliferation and survival were measured by MTS (A) and BrdU incorporation (B) assays. At 24, 48 and $72 \mathrm{~h}$, the increase in proliferation of tumor cells was assessed. At each time point, the mean fold increase in proliferation and survival of Si-LEDGF cells was statistically less than that in scrambled siRNA-transfected cells (Figures 4A and $B$ ).

Our next step was determining whether LEDGF knockdown cells would take a relatively longer time to attain monolayer confluency compared with normal PWR-1E or scrambled SiControl cells. Cells were cultured in 6-well plates, and chase culture was carried out up to $96 \mathrm{~h}$ and photomicrographed (Figure 4C). Comparisons between PWR-1E or Si-Control and Si-LEDGF at different time points demonstrated that Si-LEDGF cells displayed decreased migration/proliferation (Figures 4Ci, j, k and I) compared with PWR-1E (Figures 4Ca-d) or Si-Control (Figures $4 \mathrm{Ce}-\mathrm{h}$ ).

Knockdown of LEDGF induced S-phase and G2-M arrest through downregulation of cyclin B1 in DU145 cells. To characterize the process of inhibition of proliferation of SiLEDGF-DU145 cells, we analyzed the cell cycle progression by FACS analysis as described elsewhere. ${ }^{32}$ As shown in Figure $5 \mathrm{a}$, transfection of scrambled or control siRNA did not affect the cell cycle profile, whereas Si-LEDGF-transfected cells showed an obvious decrease in the percentage of cells with 2N DNA ( $\sim 36.21 \%)$ content (Figure 5a). Interestingly, LEDGF knockdown caused an enrichment of cells in the S-phase $(51.31 \%)$ and G2 phase ( 12.48\%). However, a corresponding decrease of cells in the G1 phase ( $\sim 36.21 \%$ ) was observed compared with Si-control cells ( $\sim 62.19 \%)$, indicating that LEDGF-deficient cells having an impaired cell cycle (Figure 5a). As before mitotic centrosome activation at the G2-M transition, cell cycle progression through $\mathrm{G} 2$ to mitosis is accompanied by an accumulation of cyclin B1, it was appropriate to examine whether LEDGF knockdown cells contained reduced levels of cyclins. Data revealed a significant reduction in the expression of G2-regulatory kinase cyclin B1 (Figure 5b, lane 2) in Si-LEDGF cells.

\footnotetext{
LEDGF-depleted DU145 cells displayed increased expression of Bax and underwent apoptosis. As expected, analysis with TdT-mediated dUTP-biotin nick end labeling (TUNEL) staining revealed more apoptotic nuclei in Si-LEDGF-DU145 cells, with approximately $37 \%$ of the cell population showing characteristic apoptotic nuclei (Figures 6Aa, b and B). As shown in Figure 6C, LEDGF knockdown cells revealed a significant increase in the expression of Bax protein (Figure 6Ca, lane 2). Next, we examined the expression pattern of $\mathrm{Bcl} 2, \mathrm{Bcl}_{-\mathrm{XL}}$ and procaspase or
}

caspases 9. Data revealed a significant reduction in expression of survival molecules $\mathrm{Bcl} 2$ (Figure $6 \mathrm{Cb}$, lane 2) and $\mathrm{Bcl}-\mathrm{xL}$ (Figure 6Cc, lane 2) and caspase 9 was activated; two apparent bands of molecular weight $\sim 47 \mathrm{kDa}$ (procaspase 9 ) and $\sim 35 \mathrm{kDa}$ (cleaved caspase-9) could be observed, and the level of cleaved band (active form) was found to be increased in Si-LEDGF-deficient cells (Figure 6Cd, lane 2).

\section{LEDGF depletion attenuated cell invasion and migration} and stabilized activation of ERK/Akt. To address the role of LEDGF in PC invasion and metastasis, siRNA-LEDGFand scrambled Si-Control-DU145 cells were allowed to invade through polycarbonate membrane inserts. As shown in Figures $7 A$ and $B$, LEDGF knockdown showed reduced invasive characteristics for cells (25\% cell invasion) compared with Si-Control cells (80\% cell invasion). To further examine the involvement of LEDGF in invasive behavior, we performed an in vitro wound-healing assay using LEDGFdepleted DU145 cells. Confluent and quiescent monolayers of scrambled Si-Control or Si-LEDGF stable DU145 cells were wounded. At $24 \mathrm{~h}$ later, cell migration or the distance of cell migration to the wound area was measured (Figure $7 \mathrm{C}$, compare $\mathrm{Ca}$ versus $\mathrm{Cb}$; $\mathrm{Cc}$ versus $\mathrm{Cd}$ ). The wound-healing ability of LEDGF-depleted cells was much slower than that of scrambled Si-Control (Figures 7C and D).

Next we tested whether Hsp27-depedent ERK/Akt pathway is activated in DU145 cells, and whether that pathway could be inhibited by knocking down LEDGF. Western analysis revealed the deactivation of ERK1/2 and Akt proteins in Si-LEDGF-transfected cells (Figure 7E, lane 2), suggesting that LEDGF stimulation of cancer cell progression may be associated with the ERK/Akt pathway.

\section{LEDGF overexpression reversed the stabilized viability, proliferation and invasive behavior of LEDGF-depleted DU145 cells. To determine whether re-overexpression of LEDGF would reverse the stabilization of the viability, proliferation and invasiveness of Si-LEDGF cells, we over- expressed the Si-Control and Si-LEDGF cells with pEGFP- vector or pEGFP-LEDGF. Cell proliferation and viability were assessed after 24, 48 and $72 \mathrm{~h}$ as stated in Materials and Methods. At all time points, the viability (Figure $8 \mathrm{~A}$ ) and proliferation (Figure $8 \mathrm{~B}$ ) rate was significantly increased in Si-LEDGF cells overexpressed with LEDGF. Interestingly, Invasive assay using scrambled Si-Control and Si-LEDGF cells overexpressed with pEGFP-vector or pEGFP-LEDGF (Figures $8 \mathrm{C}$ and $\mathrm{Dd}$ ), revealed an increase in invasive potential of cells re-overexpressed with LEDGF.}

Figure 2 Transactivation assay showing LEDGF-dependent activation of Hsp27 in DU145 cells and enhanced cell migration. (A) Representative images showing localization pattern of pEGFP-V (a) or pEGFP-LEDGF (b) in DU145 cells following transfection. Cells were transfected with pEGFP-vector or pEGFP-LEDGF. After $48 \mathrm{~h}$ cells were subjected to fluorescence microscopy and photomicrographed. (B) LEDGF overexpression enhanced the transcription of Hsp27. Data showing the real-time PCR analysis of Hsp27 and LEDGF mRNA in cells overexpressing EGFP-LEDGF plasmids as indicated $\left({ }^{* *} P<0.001\right)$. (C) Upper panel, diagrammatic representation of Hsp27 promoter containing LEDGF binding elements linked to CAT reporter plasmid. Lower panel, CAT-ELISA performed in DU145 cells after co-transfection with empty CAT vector (black bar) or pCAT-Hsp27 along with varying concentrations of pEGFP-LEDGF (gray bars). (D) DU145 cells overexpressing LEDGF displayed higher migration activity. Wound-healing assay was performed in DU145 cells transfected either with pEGFP-vector or pEGFP-LEDGF. Images are representatives from three independent experiments. Green shows migration of cells transfected with either pEGFP-vector (a, c, e and g) or pEGFP-LEDGF (b, d, $f$ and $h$ ). Migration distance was calculated using NIS-Elements BR 3.10 image analyzer software (Nikon, Elgin, IL, USA) and is shown as a histogram (right panel, black bar versus gray bar). Data represent the mean \pm S.D. from three independent experiments $\left({ }^{\star \star} P<0.001\right)$ 
LEDGF knock down cells overexpressing Hsp27, reactivated ERK1/2 and Akt phosphorylation, regained its viability, proliferation and migratory behavior. To examine whether overexpression of Hsp27, the downstream target of LEDGF, in LEDGF-depleted cells could reverse the process displaying tumorigenic properties, we ectopically expressed Hsp27 by transfecting pCMV-Hsp27 (1 and $2 \mu \mathrm{g}$ ) into Si-LEDGF (LEDGF-depleted) and Si-Control cells. First,

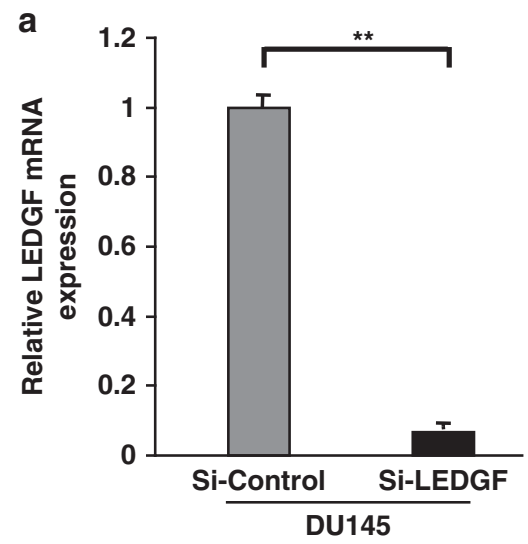

b
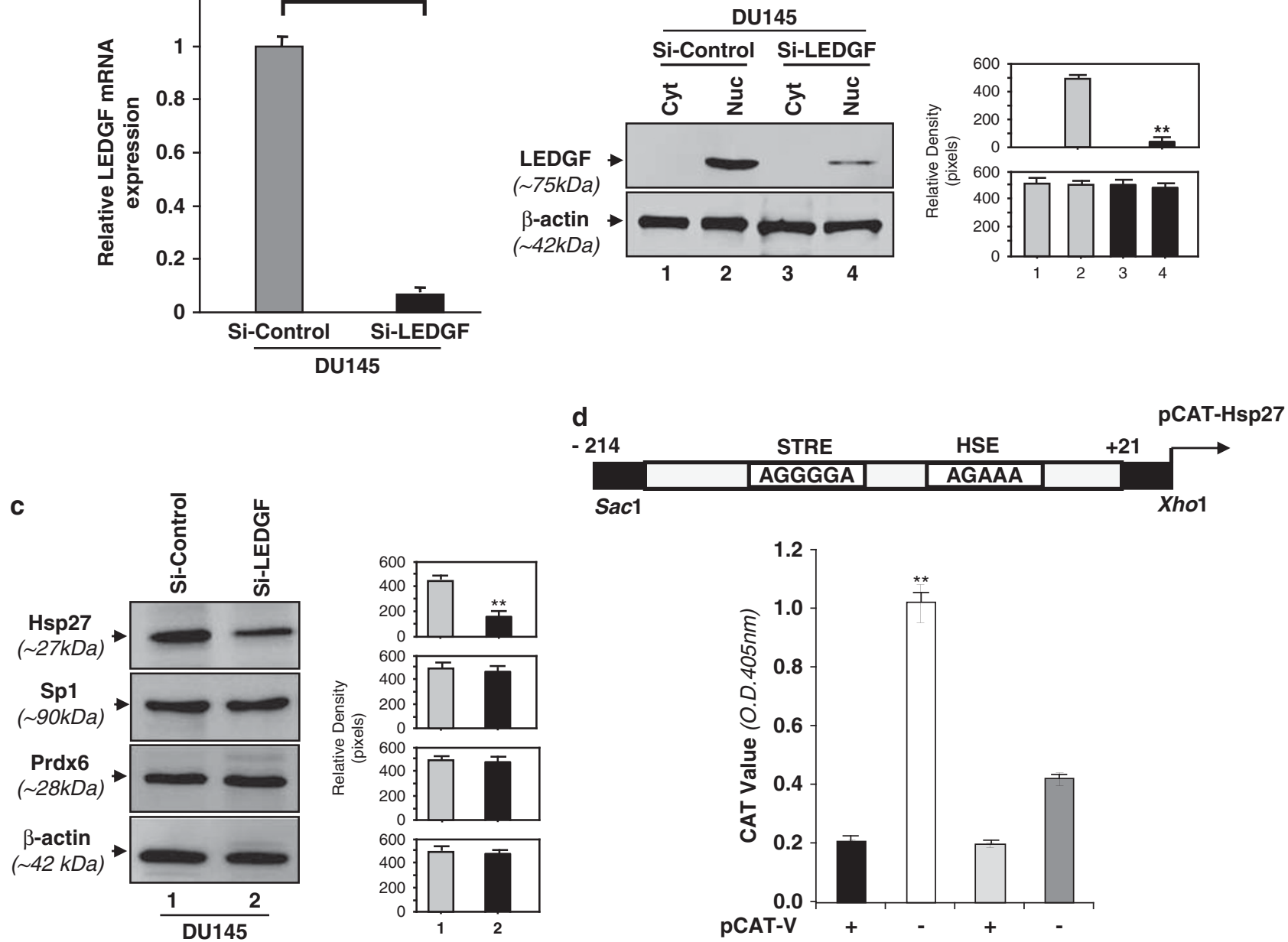

Sac1
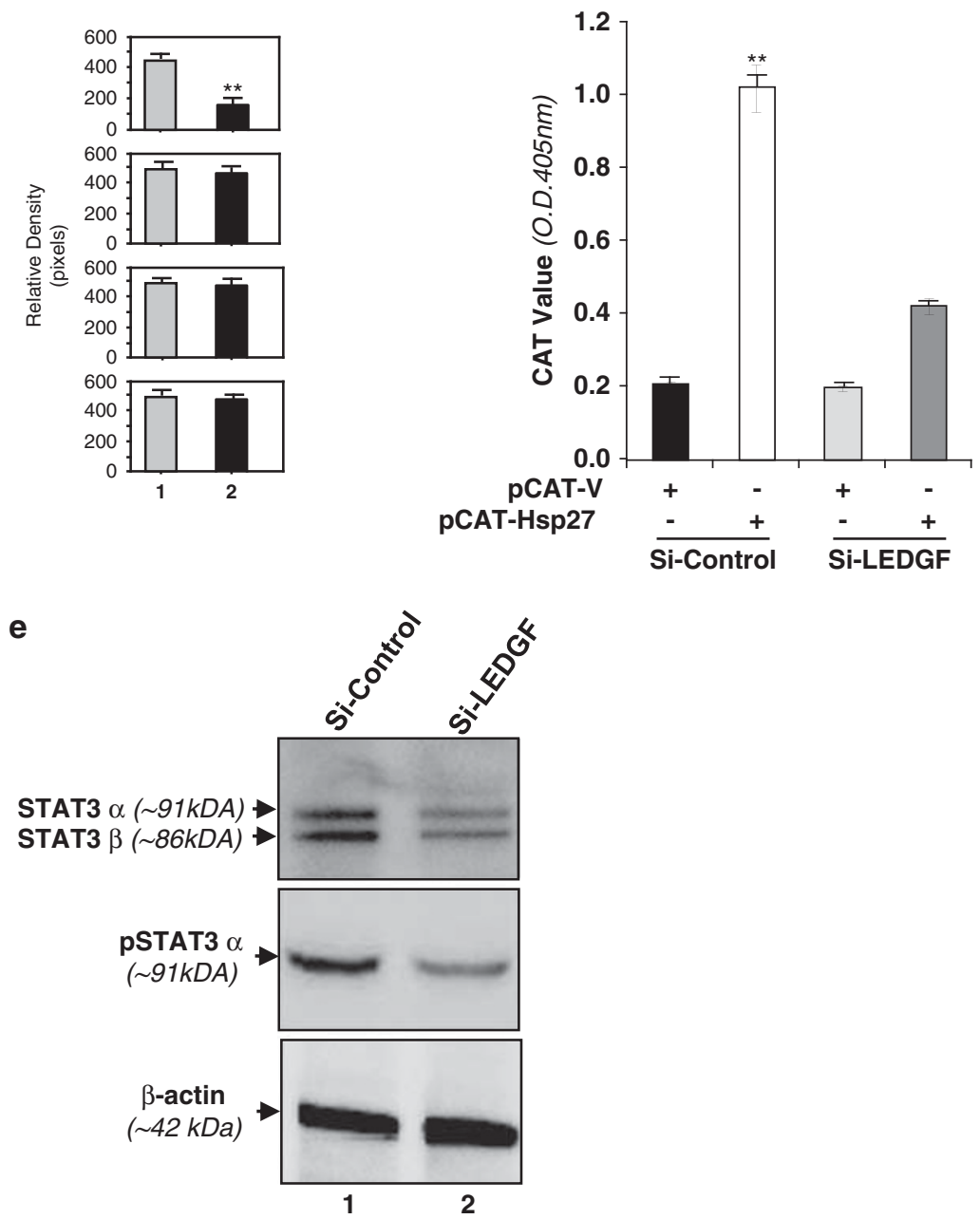
A

MTS assay

$\rightarrow$ PWR-1E

--DU145 Si-Control

$\leftarrow$ DU145 Si-LEDGF

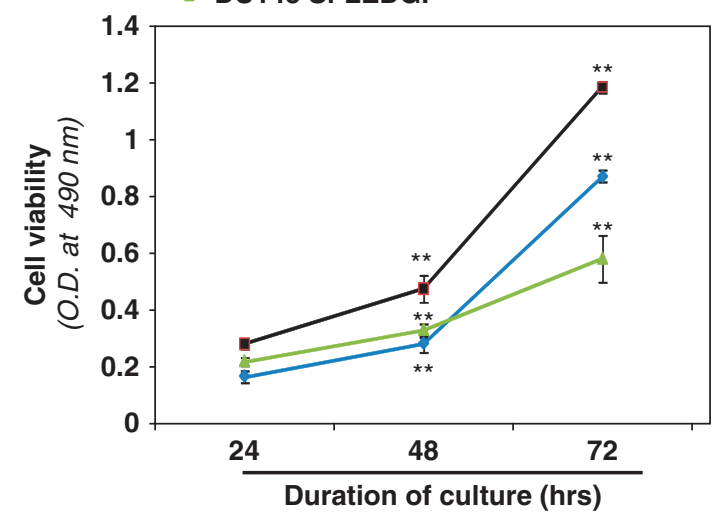

C
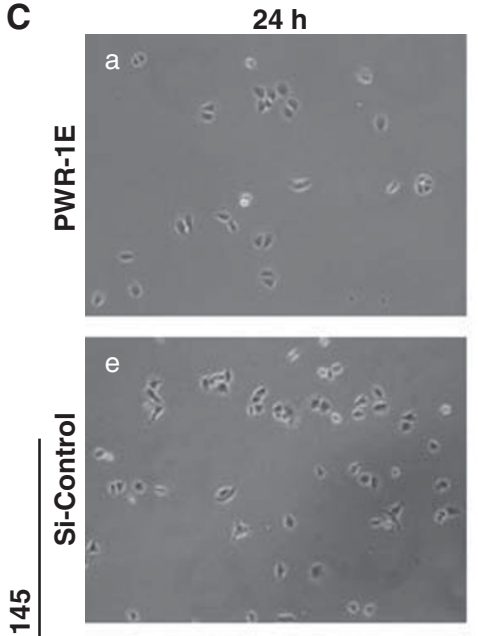

5

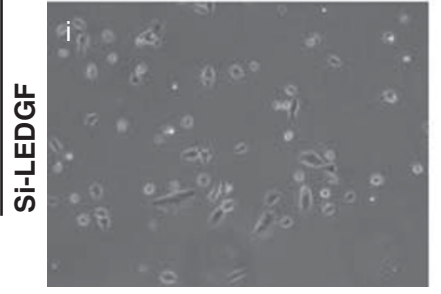

$48 \mathrm{~h}$
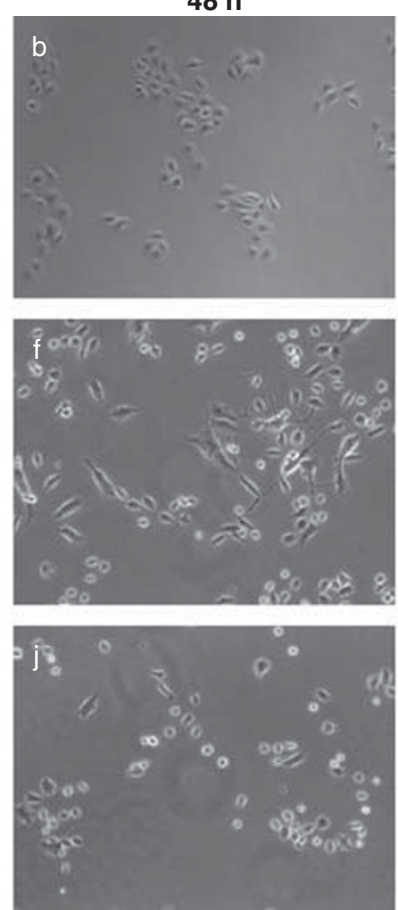

B

\section{$B r d U$ incorporation assay}

$\rightarrow$ PWR-1E

-DU145 Si-Control

\DU145 Si-LEDGF

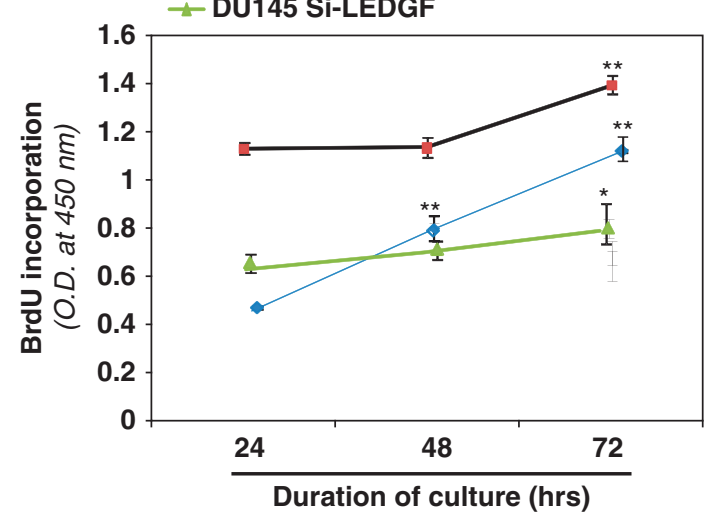

$72 \mathrm{~h}$
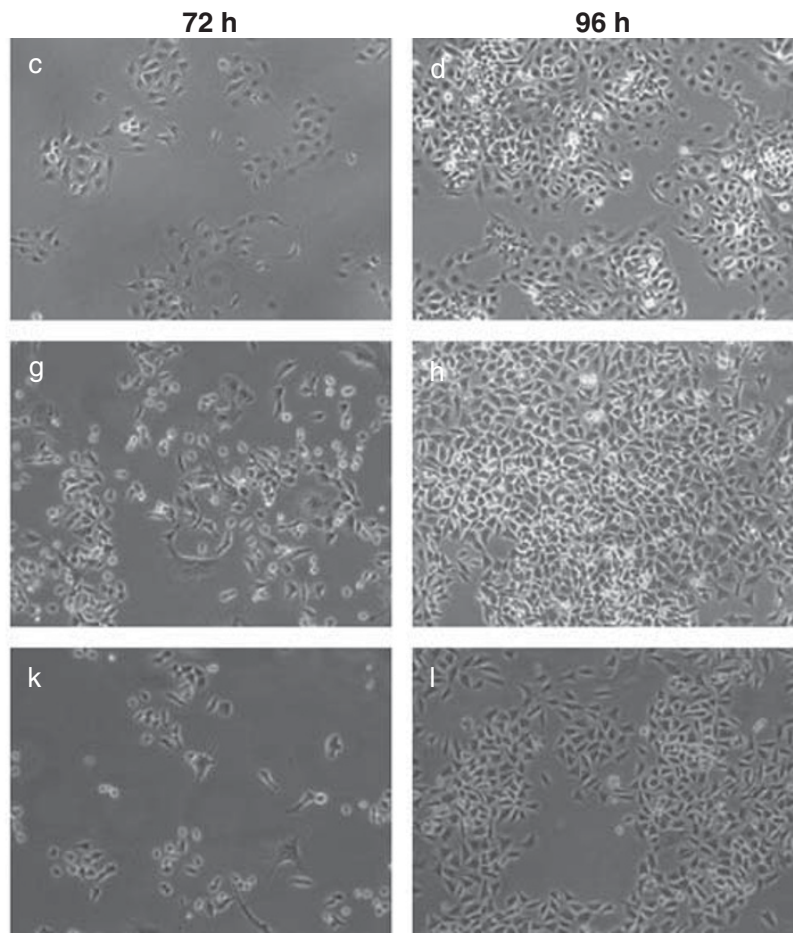

Figure 4 LEDGF depletion decreased the survival and proliferation of DU145 cells. (A) Graph showing the viability of Si-Control-and Si-LEDGF-transfected cells compared with PWR-1E normal prostate epithelial cells. Cells were harvested and processed for cell viability assay at different time points by MTS assay as depicted. (B) BrdU incorporation assay performed to evaluate the proliferation in LEDGF-depleted cells. Cells were labeled with BrdU for the last $2 \mathrm{~h}$ of culture and BrdU incorporation into DNA was measured by colorimetric assay followed by absorbance measurement at $450 \mathrm{~nm}$ as described by the company's protocol (Roche Diagnostics GmbH). Data represent the mean \pm S.D. from three independent experiments ( $\left.{ }^{* *} P<0.001 ;{ }^{*} P<0.01\right)$. (C) Representative photomicrographs of cultured cells attaining monolayer confluency (PWR-1E, a-d; Si-Control, e-h; Si-LEDGF, i-l). Images were taken at different time intervals as described in (C) with the aid of phase contrast microscope equipped with camera (Nikon Eclipse Ti-U phase contrast, Elgin, IL, USA)

Figure 3 LEDGF knockdown experiments and co-transfection assay in DU145 cells showing LEDGF-dependent expression and transcription of Hsp27. (a) Total RNA was isolated from DU145 cells of stably expressing Si-LEDGF (gray bar) or scrambled siRNA (black bar) and subjected to real-time PCR analysis for LEDGF mRNA. Levels of expression were normalized with the Cp values obtained from $\beta$-actin. Data represent the mean \pm S.D. from three independent experiments ( $\left.{ }^{\star \star} P<0.001\right)$. (b) Western analysis performed with cell lysates isolated from the Si-LEDGF or Si-Control cells using anti-LEDGF antibody. Lower panel, membrane probed with $\beta$-actin antibody as loading/internal control. Each band of blot was quantified using densitometer shown at right (black bar versus gray bar). (c) Representative western analysis experiments illustrating the expression of Hsp27 (upper panel) in Si-LEDGF (lane 2) or Si-Control (lane 1) cells. Lower panel, membrane probed with $\beta$-actin antibody as loading/internal control. Representative western analysis of Sp1 and Prdx6 proteins (middle panel) validating the specific knockdown of LEDGF and its specific effect on downregulation of Hsp27. Each band of blot was quantified using densitometer shown at right (black bar versus gray bar). (d) Upper panel, diagrammatic representation of Hsp27 promoter containing LEDGF responsive elements linked to CAT basic vector. Lower panel shows the CAT-ELISA performed in stably transfected Si-LEDGF or scrambled siRNA DU145 cells following transfection with empty CAT vector (black and light gray bars) or pCAT-Hsp27 (open and gray bars). Data represent the mean \pm S.D. from three independent experiments ( $\left.{ }^{*} P<0.001\right)$. (e) LEDGF-depleted DU145 cells showed decreased total and phosphorylated forms of STAT3. Western analysis performed with the lysate prepared from Si-Control and Si-LEDGF cells. As shown in the Figure (lane 2), the level of STAT3 was decreased in LEDGF-depleted cells 

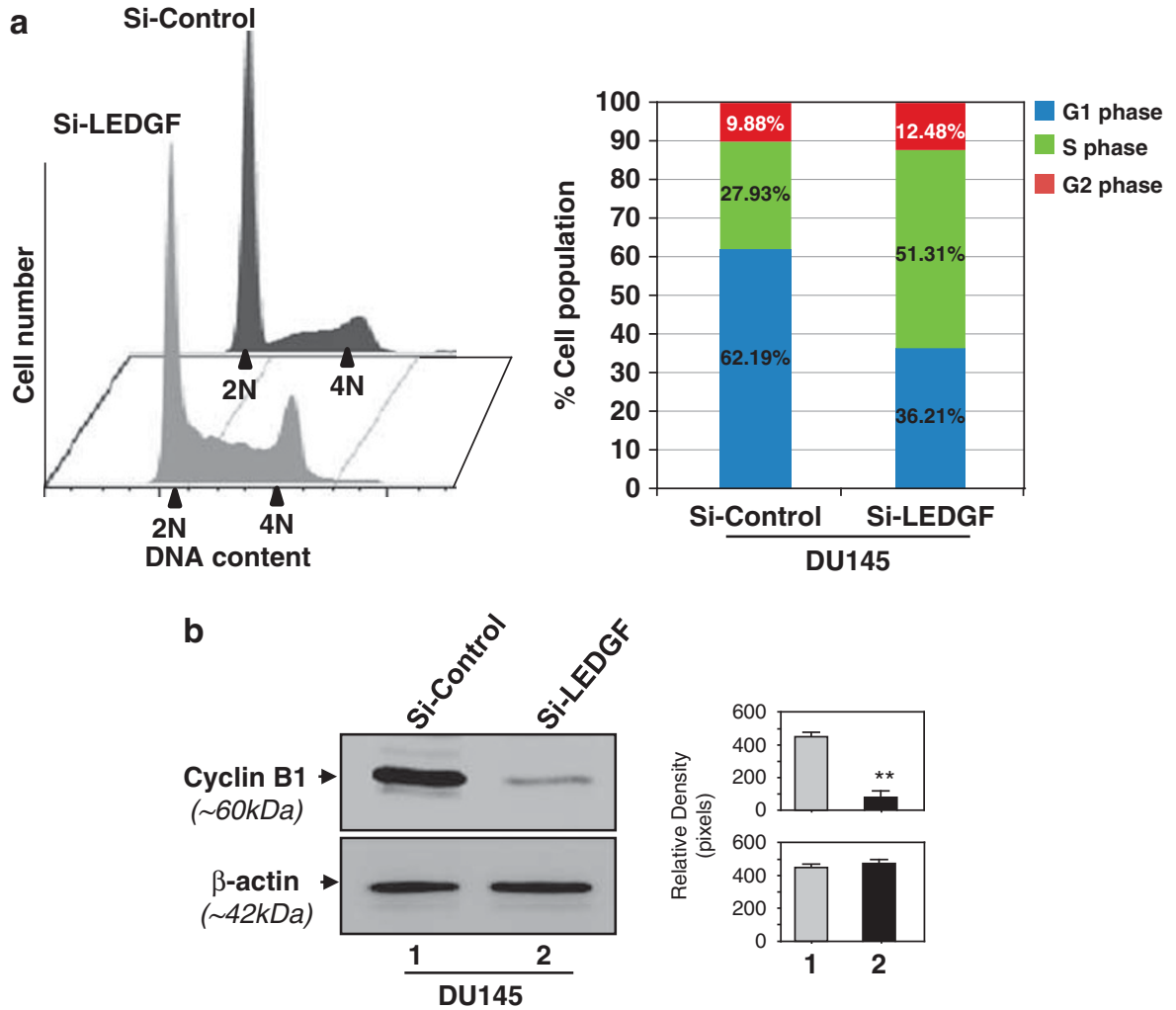

Figure 5 LEDGF depletion induced S-phase and G2-M cell cycle arrest and failure to accumulate cyclin B1. (a) Si-Control and Si-LEDGF stably transfected DU145 cells were plated in $100 \mathrm{~mm}$ dishes and cultured for $24 \mathrm{~h}$. Cells were harvested and hypotonically lysed in a PI solution to stain the DNA. Nuclei were analyzed for DNA content by flow cytometry. Percentage of cell population at G1, S and G2 phases are shown on the right (compare Si-Control and Si-LEDGF). (b) Western analysis to examine altered expression of cell cycle regulatory proteins. Decreased expression of cyclin B1 was observed in LEDGF-depleted cells (upper panel, lane 2). Lower panel, membrane probed with $\beta$-actin antibody as loading/internal control. Each band of blot was quantified using densitometer shown on the right (black bar versus gray bar, ${ }^{* *} P<0.001$ )

we confirmed the LEDGF silencing (Figure $9 \mathrm{Aa}$ ) and its dose-responsive effect on Hsp27 expression (Figure 9Ab). The same membrane was reprobed with ERK and Akt antibodies specific to phosphorylated or non-phosphorylated forms. Interestingly, we could observe reactivation of both ERK1/2 (Figure 9Ac, right panel; lanes 2 and 3) and Akt (Figure 9Ae, right panel; lanes 2 and 3 ) proteins, indicating involvement of LEDGF in PC progression is through Hsp27ERK/Akt signaling.

Next, we became interested to know whether aboveobserved events, reactivation of ERK $1 / 2$ and Akt may also reverse its viability, proliferation and migration behaviors. We found that indeed, the overexpression of Hsp27 in LEDGFdepleted cells, significantly reversed its viability (Figure 9B), proliferation (Figure 9C) and migratory behavior (Figure 9Dh, $\mathrm{i}, \mathrm{k}$ and I). Conversely, Si-Control cells overexpressed with Hsp27 further enhanced its proliferation (Figures 9A and B) and migratory behavior (Figures 9Db, c, e and f).

Ectopic expression of LEDGF in normal prostate epithelial cells, PWR-1E, transformed them into invasive cells. To determine whether normal prostate cells overexpressing LEDGF initiate tumorigenesis, we transfected PWR-1E cells with $1 \mu \mathrm{g}$ of pEGFP-LEDGF (Figure 10A). The ectopic expression of LEDGF enhanced the survival (Figure 10B) and proliferation (Figure 10C) of these cells as evidenced by viability (MTS) and BrdU assays. Furthermore, in a parallel experiment, these cells were also used for invasion assay. Data showed an induction of invasiveness in these cells (Figures 10D and Eb).

\section{Discussion}

Our present work showed that androgen-independent DU145 and androgen-dependent PC-3 and LNCaP PC cell lines tested using expression analysis displayed aberrant expression of LEDGF and Hsp27. Importantly, the expression level of Hsp27 was well correlated with abundance of LEDGF protein. We also found that normal cells, PWR-1E when overexpressed with LEDGF led to expression of tumorigenic property, arguing that LEDGF overexpression causes initiation of tumorigenesis (Figures $10 \mathrm{D}$ and E). Furthermore, DU145 having aberrant expression of LEDGF when overexpressed with LEDGF revealed more aggressive tumorigenic properties (Figure 2). In the above scenario we concluded that transcriptional protein LEDGF is a crucial factor required for progression and initiation of tumorigenesis. LEDGF achieved this by upregulating Hsp27, and thereby stimulating the survival signaling Akt/ERK pathway(s). Effective knockdown of LEDGF in DU145 cells, abolished its tumorogenic properties through downregulation of Hsp27 and deactivation of ERK/Akt proteins. Interestingly, LEDGF- 
A
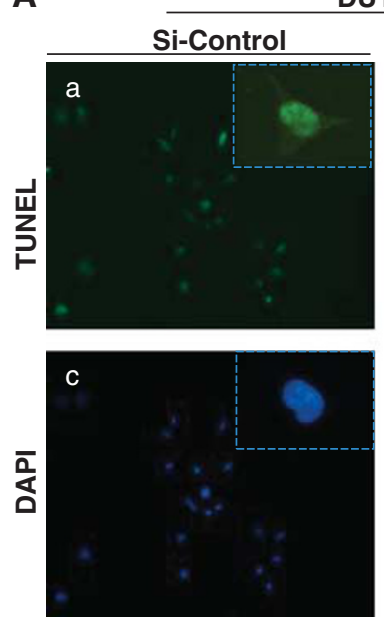

DU145
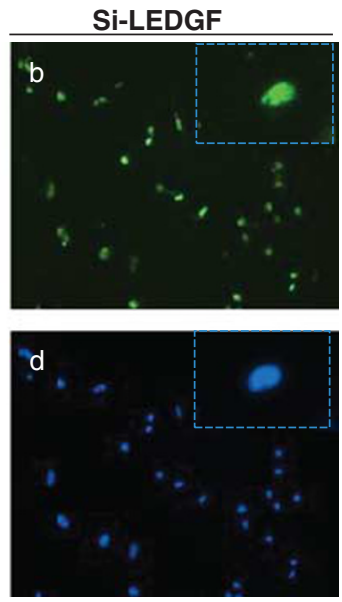

C

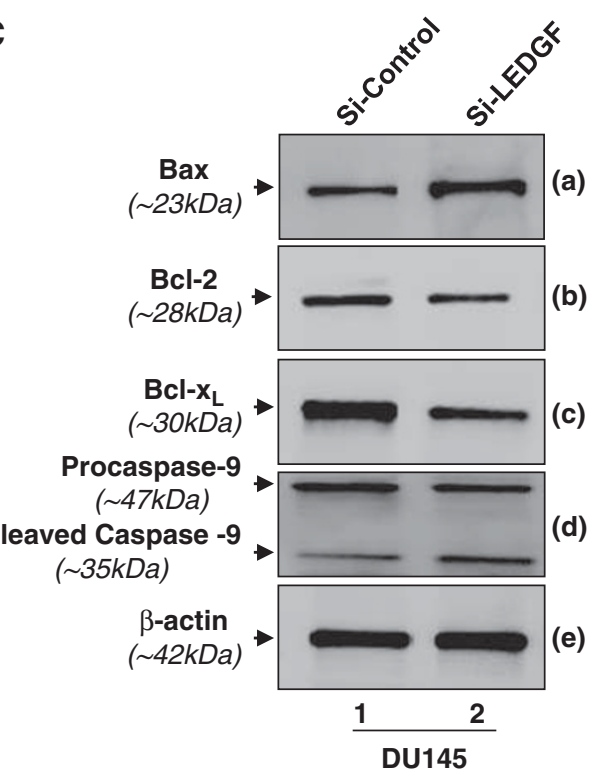

B
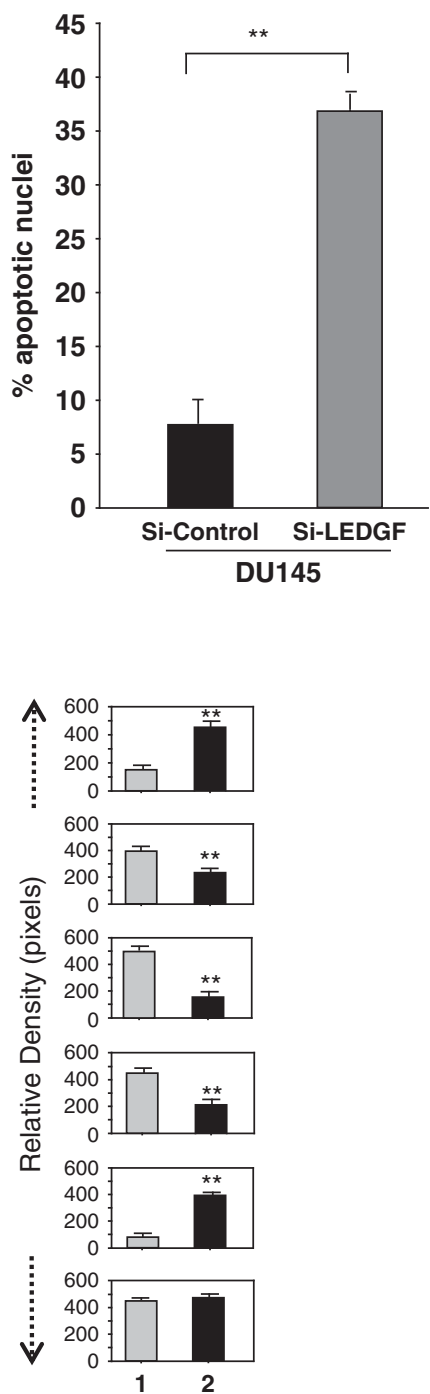

Figure 6 LEDGF depletion promotes apoptosis in DU145 cells. (A) Determination of apoptosis in scrambled Si-Control- or Si-LEDGF-transfected cells by TUNEL staining Images were taken in FITC (a versus b) and DAPI (c versus d) filters by fluorescent microscope equipped with camera (A) (Nikon Eclipse Ti-U fluorescent microscope). The number of apoptotic nuclei was counted manually. Three randomly selected fields were taken to quantify the apoptotic cells, and percentage was calculated and is shown as histogram (B, black bar versus gray bar). Data represent the mean \pm S.D. from three independent experiments $\left.{ }^{* *} P<0.001\right)$. (C) Representative images of western analysis for apoptotic signaling-related proteins (Bax, Bcl2, Bcl-xL, procaspase 9 and cleaved caspase 9). Lower panel shows $\beta$-actin band as internal control. Each band of blot was quantified using densitometer shown on the right (compare gray bar versus black bar)

depleted DU145 cells when overexpressed with LEDGF or Hsp27, a reversal of tumorigenic properties occurred in these cells through the reactivation of ERK1/2/Akt proteins (Figure 9), supporting the hypothesis that LEDGF has its role in cancer progression through the upregulation of Hsp27. Hsp27 has been reported to interact with STAT3, a crucial transcription factor implicated in the maintenance and antiapoptotic status of cancerous cells. ${ }^{33,34}$ We found that LEDGF-depleted cells exhibited reduced level of STAT3 and phosphorylated forms (Figure 3e).

Furthermore, LEDGF has recently attracted attention owing to its frequent aberrant expression in tumor cells, and to its cytoprotective and chemoresistance properties. ${ }^{30}$ Our data showed that it is possible to markedly reduce the expression of LEDGF in DU145 cancer cells and its tumorigenicity/ metastasis, by the use of Si-LEDGF (Figure 7E). Furthermore, the increased LEDGF expression in prostate tumors and $\mathrm{BPH}$ compared with normal prostate tissue suggests that this protein might be upregulated during prostate carcinogenesis or development of inflammatory conditions of the prostate. ${ }^{18,30}$ Its relatively high expression in prostate tumors and their adjacent 'normal' tissue is likely induced by inflammation and oxidative stress, key factors underlying prostate carcinogenesis. ${ }^{35}$ Inflammation and oxidative stress are associated with development of $\mathrm{BPH}$, which may explain our observation that LEDGF is also strongly expressed in 
A

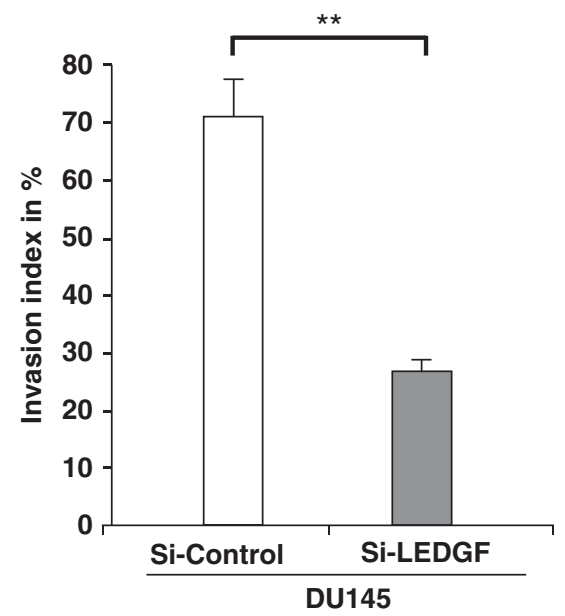

C

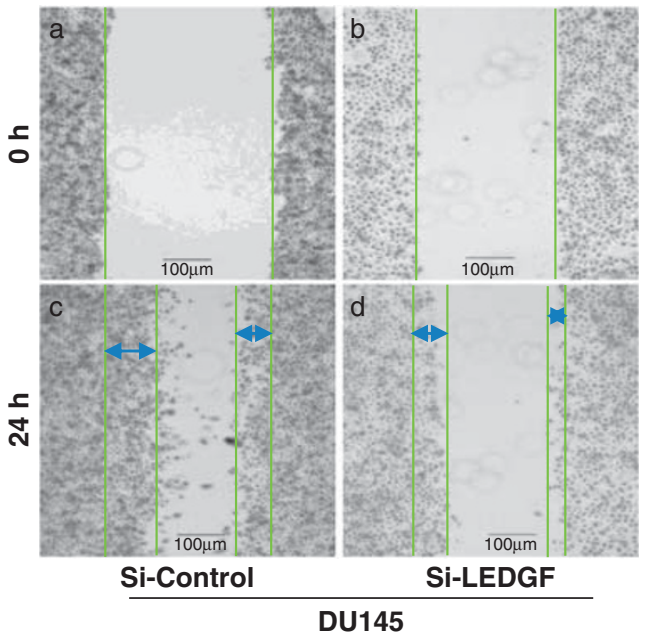

B
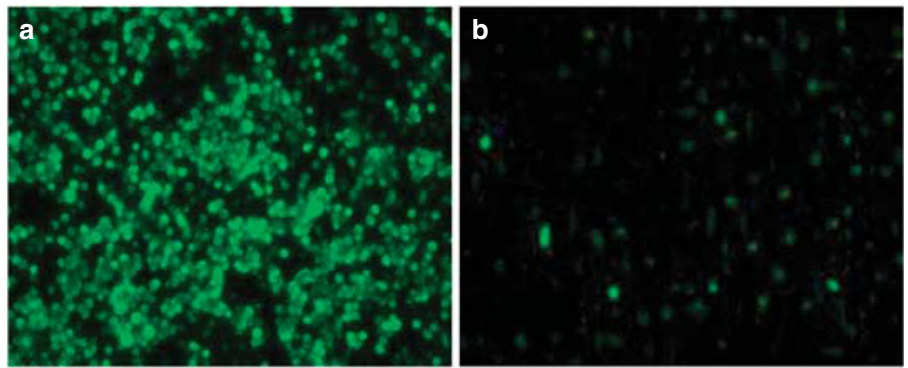

Si-LEDGF

DU145

D

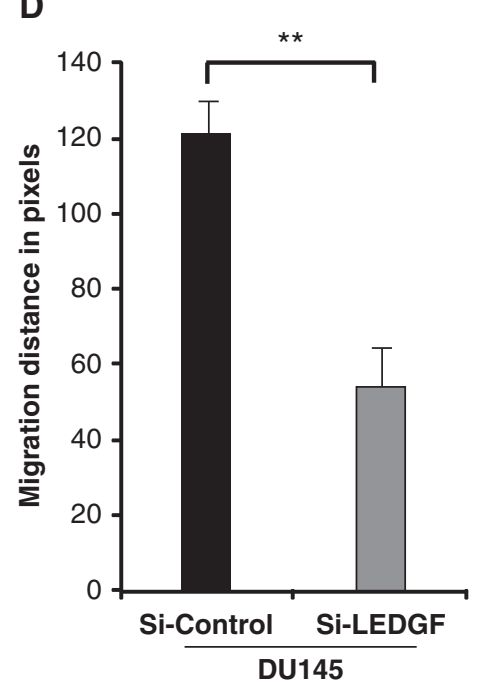

E

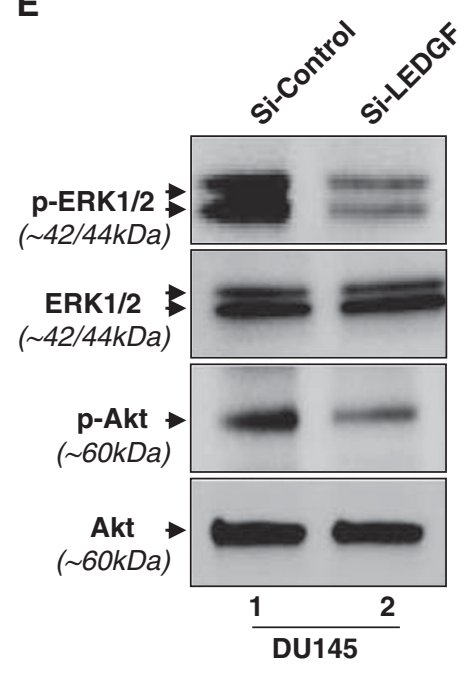

Figure 7 Knockdown of LEDGF attenuated the invasiveness and migration of DU145 cells and thereby deactivated ERK1/2/Akt signaling. (A) Cell invasion assay was carried out to evaluate the invasive behavior of cells after LEDGF depletion. Invasion index in percentage was calculated (open bar versus gray bar). Data represent the mean \pm S.D. from three independent experiments $\left({ }^{*} P<0.001\right)$. (B) The invaded cells on the membrane were stained with CyQunt $\mathrm{GR}$ dye and images were captured under FITC filter by Nikon Eclipse Ti-U fluorescent microscope equipped with camera. Images are representatives from three independent experiments (a, Si-Control; b, Si-LEDGF). (C) Images from wound-healing assay performed to assess the role of LEDGF in prostate carcinoma cell migration. Si-Control (a and c) and Si-LEDGF (b and d) cells were seeded in $60 \mathrm{~mm}$ petri plates and assay was performed. (D) Histogram showing the migration distance calculated from wound-healing assay (black bar versus gray bar). Data represent the mean \pm S.D. from three independent experiments ( $\left.{ }^{* \star} P<0.001\right)$. (E) Western analysis performed to analyze the phosphorylation status of major MAPK kinases, ERK1/2 (upper panel) and Akt (third panel from the top). Total cell lysate from both Si-Control and Si-LEDGF cells were resolved on 10\% SDS-PAGE and immunoblotted with anti-pERK1/2 or anti-ERK1/2 and anti-pAkt or anti-Akt antibodies. Level of phosphorylated and dephosphorylated forms of ERK1/2 and Akt are shown. Images are representatives from three independent experiments

human prostate carcinomas, and this enhanced expression in cancer cells such as DU145 may be a major event in progression of cancer (Figures 7B-D).

Moreover, Hsp27 is a stress-induced molecular chaperone that is highly expressed in castrate-resistant PC and other cancers, and is often associated with metastasis and poor prognosis. ${ }^{36}$ In the present study, we observed that LEDGF was aberrantly expressed, and the transactivation of LEDGF promoter was much higher in human prostate carcinoma cells, DU145. Interestingly, the effective depletion of LEDGF resulted in a decreased level of Hsp27 and promoter activity in these cells. However, the effective knockdown of LEDGF in DU145 cells led to a significant decrease in their proliferation rate as evidenced by BrdU assay (Figure 3) and delayed monolayer confluency. Overexpression/re-overexpression of LEDGF significantly increased the proliferative property and viability in these cells as examined by BrdU and MTS assays, respectively, emphasizing the indispensable role of LEDGF in controlling cell proliferation. Also, the knockdown of LEDGF reversed the apoptotic signaling in cancer cells, as shown by an increase in Bax and cleaved caspase 9 expression and downregulation of procaspase $9, \mathrm{Bcl} 2$ and $\mathrm{Bcl}-\mathrm{xL}$ proteins (Figure 6D). Initiation of mitosis is known to be regulated by the activation of cdc2-cyclin B complex. ${ }^{37}$ Although we could not show that cyclin B1 is the direct target of LEDGF, we did observe that silencing of LEDGF induced activation of the 
A

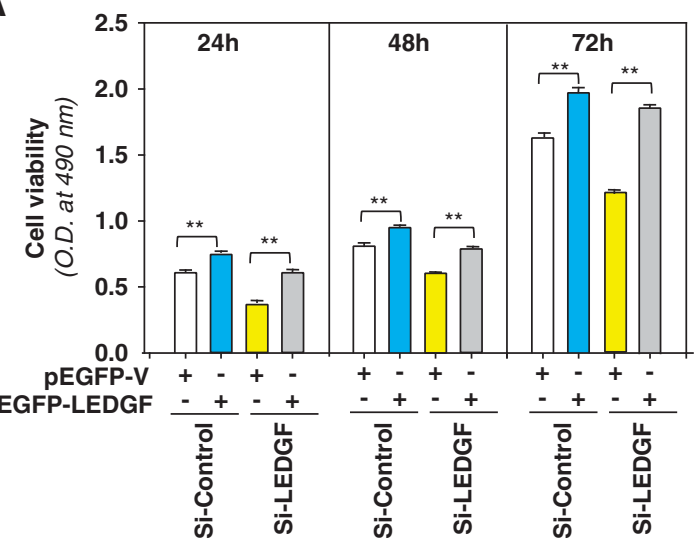

B

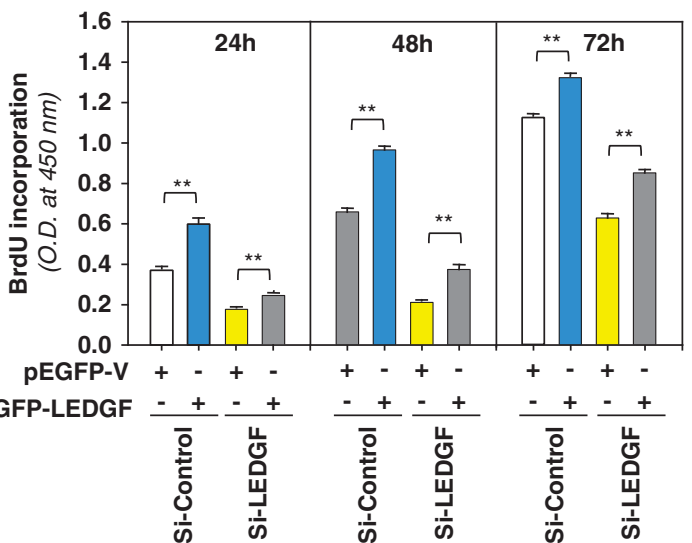

C

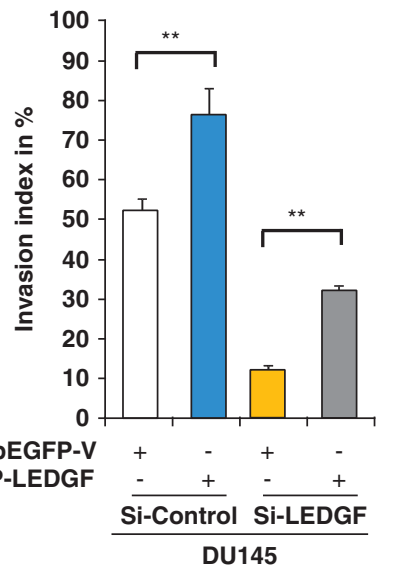

D

DU145
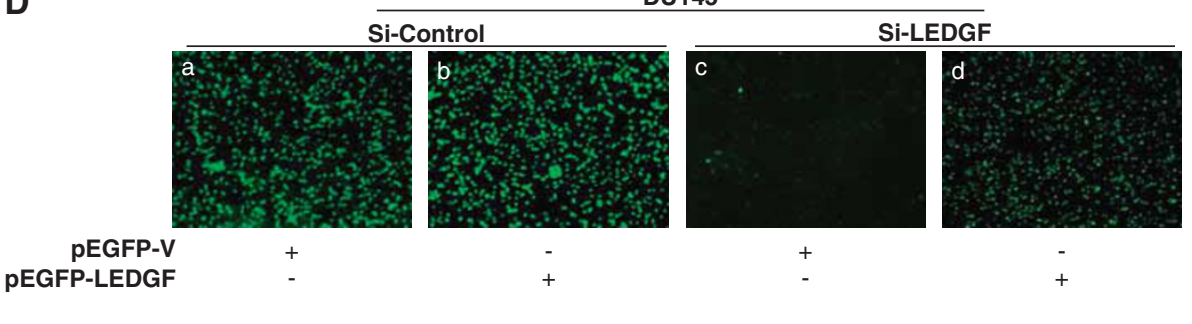

Figure 8 Re-overexpression of LEDGF in LEDGF knockdown Si-LEDGF-DU145 cells restored viability, proliferation and invasive behavior of DU145 cells. (A) Si-Control and Si-LEDGF cells were overexpressed with LEDGF. MTS assay was performed at 24,48 and $72 \mathrm{~h}$ and results are presented as histogram. (B) Si-Control and Si-LEDGF cells were overexpressed with LEDGF. BrdU incorporation assay was performed at 24,48 and $72 \mathrm{~h}$ and results are presented as histogram. (C) Histogram showing the percentage of invasion index after overexpression with LEDGF in Si-Control and Si-LEDGF cells (re-expressed) (yellow bar versus gray bar). (D) Photomicrographs of CyQuant GR-stained membrane with invaded cells shown ( $a$ and b, Si-Control; $c$ and d, Si-LEDGF). Images are of representatives from three independent experiments. Left panel shows the quantitative measurements of migration index (black bar versus gray bar). Data represent the mean \pm S.D. from three independent experiments $\left({ }^{\star \star} P<0.001\right.$ )

apoptotic signaling and S-phase and G2-arrest of the cells significantly (Figure 5a). However, we can expect more remarkable and noticeable results following synchronization of cells. However, in present study, we followed the methods of Long et al., ${ }^{32}$ to produce natural and bona-fide outcomes. We think that synchronization of cells is not feasible or cumbersome to occur in body's natural cellular microenvironment. However, in a previously published study, LEDGF was found to interact with the S-phase kinase (Cdc7:ASK) during cell cycle progression. It is well known that in higher eukaryotic cells, cyclin B1 is excluded from the nucleus by its NESdependent transport mechanism during interphase, and that NES-mediated export of proteins from the nucleus, including cyclin B1, has a role in the DNA damage-induced G2 checkpoint. Our results in this study suggest that the failure to detect cyclin B1 in the nuclear fraction of siRNA-transfected cells may be due to its DNA damage-induced G2 checkpoint. Hsp27 is also involved in the regulation of Akt, inhibiting Bax activation to enhance cell survival. We found that silencing of the LEDGF gene deactivated these two important signaling molecules. However, in this work we could be able to demonstrate the efficiency of Si-LEDGF in blocking or reducing growth and proliferation of PC cells in vitro and inhibiting progression of tumorigenic properties of PC cells. Our results from cell viability (MTS assay) and proliferation (BrdU assay) coupled with migration and invasion assays suggest that LEDGF may have role in cancer proliferation. Targeting LEDGF knockdown strategy may be useful tool to suppress growth of PC cells. Furthermore, BrdU incorporation and cell cycle assays revealed that Si-LEDGF delivery to DU145 cells induces cell arrest at $\mathrm{G} 2$ level or their progression, and that in turn leads to apoptotic cell death.

In conclusion, we demonstrated, for the first time, that the underlying mechanism involved in LEDGF deficiency blocks carcinogenesis by suppressing Hsp 27-ERK1/2 and Akt pathways in human PC cells DU145. Certainly, more work is needed for a full understanding of the role of LEDGF in PC. However, we were able to show that LEDGF knockdown should be an effective strategy in developing more effective 

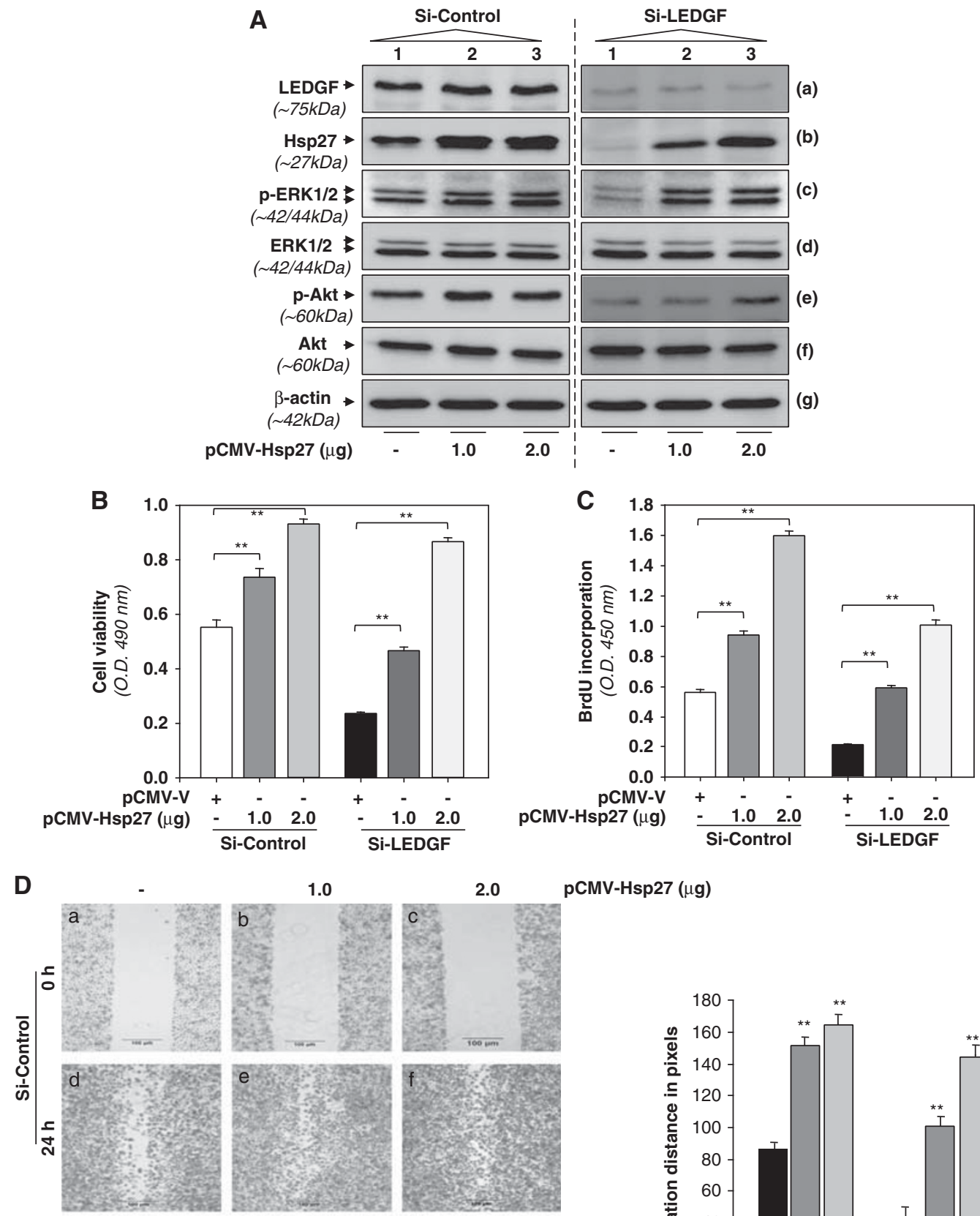

pCMV-Hsp27 $(\mu \mathrm{g})$
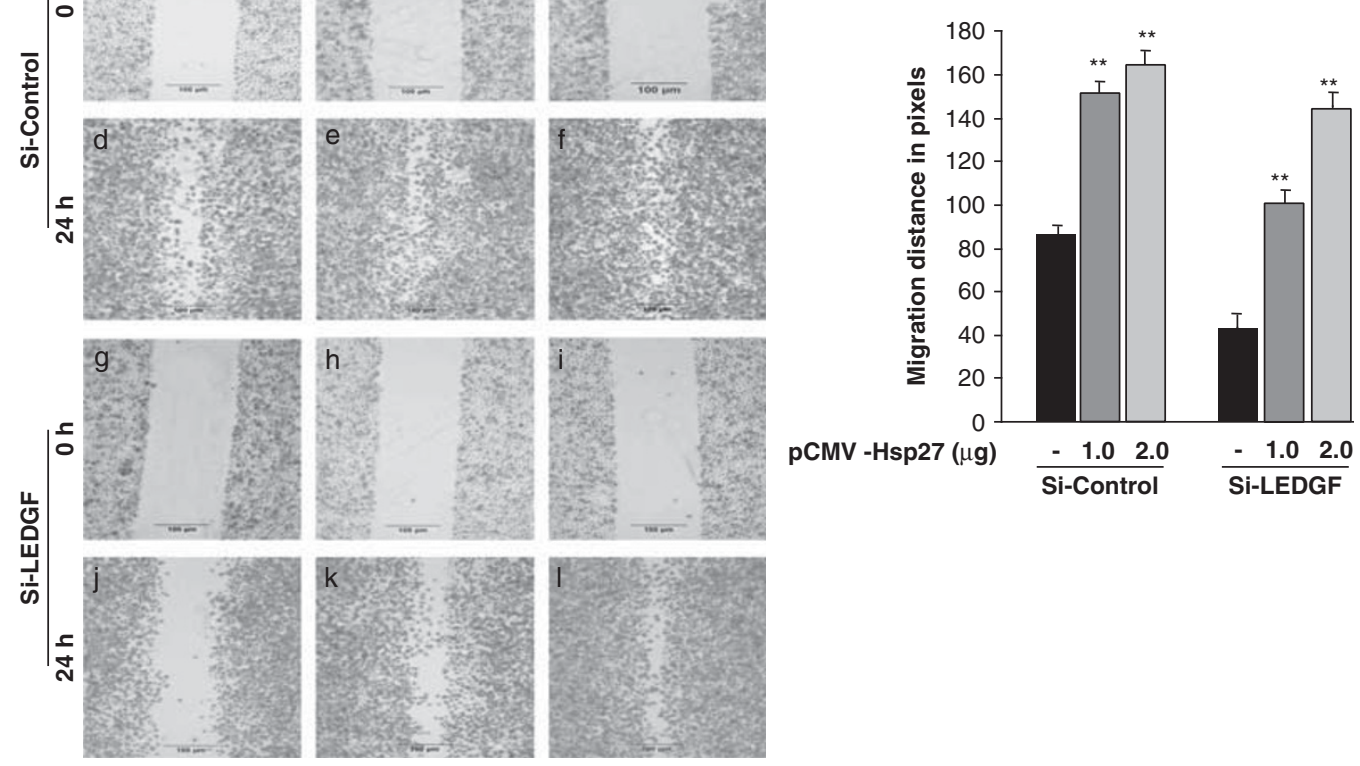
and curative anticancer therapeutics in combination with known cancer drugs, potentially leading to new treatments for metastatic PC.

\section{Materials and Methods}

Cell lines. Human prostate adenocarcinoma cell lines DU145, PC-3 and $\mathrm{LNCaP}$ were used in the present study. Observations were compared with normal prostate epithelium cell line PWR-1E wherever necessary. All the cell lines were obtained from the American Tissue Culture Collection (Bethesda, MD, USA). The DU145 cells were cultured at $37^{\circ} \mathrm{C}$ in a $5 \% \mathrm{CO}_{2}$ atmosphere in minimum essential medium (MEM) (Gibco-BRL, Bethesda, MD, USA) supplemented with $10 \%$ heatinactivated fetal calf serum (FCS). The MEM also contained $1 \mathrm{mM}$ L-glutamine, $25 \mathrm{mM}$ Hepes, $100 \mathrm{unit} / \mathrm{ml}$ penicillin and $100 \mathrm{mg} / \mathrm{ml}$ streptomycin. The PWR-1E cells were cultured in Keratinocyte serum-free medium supplemented with growth factors (Gibco-BRL). PC-3 and LNCaP cells were maintained in RPMI medium supplemented with $10 \%$ heat-inactivated FCS, $1 \mathrm{mM}$ L-glutamine, $25 \mathrm{mM}$ Hepes, $100 \mathrm{unit} / \mathrm{ml}$ penicillin and $100 \mathrm{mg} / \mathrm{ml}$ streptomycin.
Real-time PCR. Total RNA was extracted from cells using TriZol Reagent (Invitrogen, Carlsbad, CA, USA), and was used for first-strand DNA synthesis using SuperScript II (Invitrogen). PCR was performed with the following primer sequences: human LEDGF (Forward primer: $5^{\prime}$-CAGCAACAGCATCTGTTAATCTAAA-3' and reverse primer: $5^{\prime}$-GGGCTGTITACCATCATITGG-3'); human Hsp27 (forward primer: $5^{\prime}$-TCCCTGGATGTCAACCACTT-3' and reverse primer: $5^{\prime}$-GATGTAGCCATGCTCGTCCT-3') and human $\beta$-actin (forward primer: $5^{\prime}$-CCAACCGCGAGAAGATGA- $3^{\prime}$ and reverse primer: $5^{\prime}$-CCAGAGGCGTACAGGGATAG- $3^{\prime}$ ). All PCR experiments are performed in Light Cycler 480 with SYBR Green fluorescence detection (Roche Diagnostics GmbH, Indianapolis, IL, USA).

Western blot analysis. Whole-cell extracts or nuclear extracts were prepared as described earlier. ${ }^{38}$ Equal amounts of protein samples were resolved onto an SDS-PAGE. Following immunoblotting with primary antibodies; LEDGF monoclonal (BD Biosciences, San Jose, CA, USA; Cat. no. 611714), Hsp27 polyclonal (Santa Cruz Biotechnology, Santa Cruz, CA, USA; Cat. no. sc-1048), cyclin B1 (Cell Signaling Technology, Danvers, MA, USA; Cat. no. 4135), Bax (Santa Cruz Biotechnology; Cat. no. sc-7480), Bcl2 (Cell Signaling Technology;
A

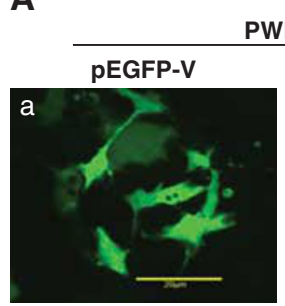

PWR-1E

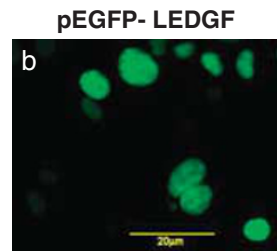

B

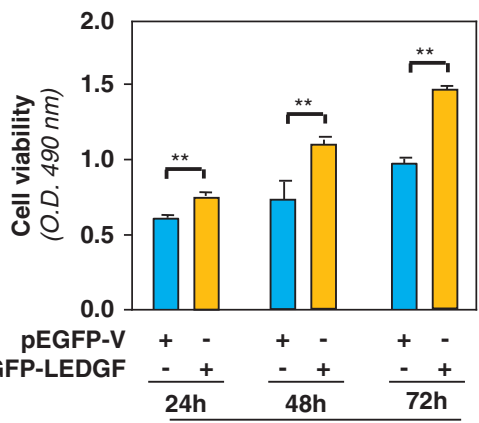

PWR-1E
C

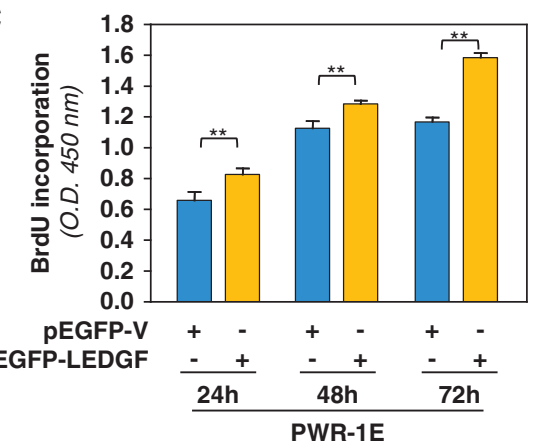

D

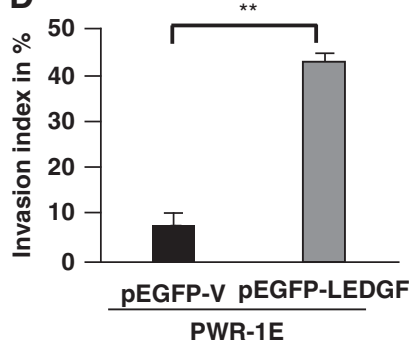

E
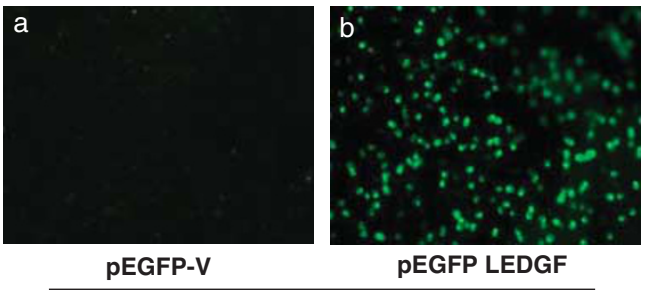

PWR-1E

Figure 10 Overexpression of LEDGF enhanced viability, proliferation and evoked invasive behavior of PWR-1E cells. (A) Representative images showing cells overexpressed with pEGFP-V or pEGFP-LEDGF in PWR-1E cells. (B) Histogram showing viability of PWR-1E cells overexpressed with pEGFP-LEDGF (yellow bars) compared with pEGFP-vector-transfected cells (blue bars) at time points shown (blue bars versus yellow bars). (C) Histogram showing proliferation of PWR-1E cells overexpressed with pEGFP-LEDGF (yellow bars) compared with pEGFP-vector-transfected cells (blue bars) at time points shown (blue bars versus yellow bars) using BrdU assay. Data represent the mean \pm S.D. from three independent experiments $\left({ }^{* *} P<0.001\right)$. (D) Histogram showing the percentage of invasion index of PWR-1E cells overexpressing EGFP-LEDGF (gray bar). Data represent the mean \pm S.D. from three independent experiments $\left({ }^{\star \star} P<0.001\right)$. (E) Photomicrographs of CyQuant GR-stained membrane with invaded cells ( $\mathrm{a}, \mathrm{pEGFP}-\mathrm{V} ; \mathrm{b}$, pEGFP-LEDGF). Images are of representatives from three independent experiments

Figure 9 LEDGF knockdown cells overexpressing Hsp27 reactivated ERK1/2 and Akt phosphorylation, regained its viability, proliferation and migratory behavior. (A) Representative images of western blot analysis performed for indicated proteins with cell lysates obtained from Si-Control (left panel) and Si-LEDGF (right panel) cells overexpressing Hsp27 of two different concentrations $1 \mu \mathrm{g}$ (lane 2) and $2 \mu \mathrm{g}$ (lane 3) of pCMV-Hsp27 or pCMV vector (lane 1)). Equal amount of plasmids were maintained with empty vector DNA in all transfections. The same membrane was used for striping and reprobed with different antibodies as indicated. Lower panel, $\beta$-actin band as internal control. (B and C) Histogram showing cell viability (B) and BrdU incorporation (C) of Si-Control and Si-LEDGF cells overexpressed with pCMV-Hsp27 compared with pCMV vector-transfected cells. Data represent the mean \pm S.D. from three independent experiments $\left.{ }^{* \star} P<0.001\right)$. (D) Si-Control and Si-LEDGF cells overexpressing Hsp27 displayed higher migration activity. Wound-healing assay was performed in Si-sontrol and Si-LEDGF cells transfected either with pCMV-Hsp27 or pCMV vector. Images are representatives from three independent experiments. Upper panel, migration of Si-control cells transfected with either pCMV vector (a and d) or pCMV-Hsp27 (b, c, e and f). Lower panel, migration of Si-LEDGF cells transfected with either pCMV vector ( $\mathrm{g}$ and j) or pCMV-Hsp27 ( $\mathrm{h}, \mathrm{i}, \mathrm{k}$ and I). Migration distance was calculated using NIS-Elements BR 3.10 image analyzer software (Nikon) and is shown as a histogram (right panel, black bar versus gray bar). Data represent the mean \pm S.D. from three independent experiments $\left({ }^{* \star} P<0.001\right)$ 
Cat. no. 2876), Bcl-xL (Santa Cruz Biotechnology; Cat. no. sc-7195), caspase-9 (Cell Signaling Technology; Cat. no. 9508), pERK1/2 (Cell Signaling Technology; Cat. no. 9106), ERK1/2 (Cell Signaling Technology; Cat. no. 9107), Akt (Cell Signaling Technology; Cat. no. 9272) and pAkt (Cell Signaling Technology; Cat. no. 4051), Prdx6 (Santa Cruz Biotechnology; Cat. no. sc-271368), Sp1 (Santa Cruz Biotechnology; Cat. no.sc-17824), STAT3 (Santa Cruz Biotechnology; Cat. no.sc-482), membrane was visualized following standard protocol and recorded with FUJIFILM-LAS-4000 luminescent image analyzer (FUJIFILM Medical system Inc., Stamford, CT, USA).

Construction of Hsp27-CAT and EGFP-LEDGF constructs. Hsp27-CAT construct was engineered as described previously. ${ }^{13}$ Briefly, a forward primer containing a Sacl site (5'-GCGTCGAGCTCTCGAATTCATTT GCTT-3') and reverse primer with a Xhol site ( $5^{\prime}$-GCTCTCGAGGTCTGCTCAGAA AAGTGC- $3^{\prime}$ ) were used to generate the fragment, which was cloned between the $E c o R l$ sites of the TA vector (Invitrogen). The Hsp27-TA construct was digested with Sacl and Xhol and promoter fragments was ligated to PCAT-Basic vector (Promega, Madison, WI, USA). A construct containing a green fluorescent protein (GFP) and LEDGF cDNA was generated with the 'living color system' (Clontech, Palo Alto, CA, USA) using the plasmid vector pEGFP-C1 (Clontech) for LEDGF protein overexpression studies. Expression construct, pCMV-Hsp27 and empty vector, $\mathrm{pCMV}-\mathrm{V}$, were purchased from Addgene (Cambridge, MA, USA).

CAT assay. The CAT assay was performed using a CAT-ELISA kit (Roche Diagnostics $\mathrm{GmbH}$ ). Cells were transfected/co-transfected with reporter construct (Hsp27-CAT) and/or EGFP-LEDGF/Si-LEDGF expression vectors. After $48 \mathrm{~h}$ of incubation, cells were harvested, and extracts were prepared and protein was normalized. CAT-ELISA was performed to monitor CAT activity, following the manufacturer's protocol. Absorbance was measured at $405 \mathrm{~nm}$ using a microtiter plate ELISA reader. Transactivation activities were adjusted for transfection efficiencies using GFP or SEAP values. The transfection experiments were carried out either with Superfactamine Reagent (Invitrogen) or using Neon Transfection system (Invitrogen).

siRNA assay. The LEDGF-specific siRNA expression plasmid was designed according to the method described earlier. ${ }^{39}$ The sequence was selected from location 1340-1360 (5'-AAAGACAGCATGAGGAAGCGA- $\left.3^{\prime}\right)$. The sense and antisense oligonucleotides with the internal loop were synthesized by Invitrogen. These were annealed and ligated into the BamHI and Hindlll sites of pSilencer 4.1-CMV hygro (Ambion, Carlsbad, CA, USA). pSilencer 4.1-pCMVhygro expressing a scrambled siRNA (Ambion) was used as a control. siRNA constructs were transfected into DU145 cell with Superfactamine Reagent (Invitrogen). At $24 \mathrm{~h}$ after transfection, stable transfected cells were selected using $400 \mu \mathrm{g} / \mathrm{ml}$ of hygromycin (Invitrogen) over a period of 9 days. Silencing was confirmed by LEDGF mRNA and protein expression.

BrdU incorporation and MTS assay. Cell proliferation assay was performed with BrdU incorporation assay kit according to manufacturer's protocol (Roche Diagnostics $\mathrm{GmbH}$ ). Briefly, equal number of cells was seeded in 96-well plates at a density of 5000 cells/well. Following incubation cells were labeled with $\mathrm{BrdU}$ for $2 \mathrm{~h}$, the OD was measured at $450 \mathrm{~nm}$. MTS assay performed to measure the viability of the cells at different time points. In brief, 5000 cells/well were seeded into 96-well plates. Following incubation with MTS dye, absorbance was measured at $490 \mathrm{~nm}$.

Flow cytometry for cell cycle and apoptosis. Scrambled Si-Controland Si-LEDGF-transfected cells were grown in T75 culture flask. After $24 \mathrm{~h}$, cells were harvested, fixed with $5 \mathrm{ml}$ of ice-cold $70 \%$ ethanol $\left(4^{\circ} \mathrm{C}\right)$. Cell pellets were collected by centrifugation and resuspended in $400 \mu \mathrm{l}$ of PBS, $50 \mu \mathrm{l}$ of propidium iodide (PI) solution $(0.6 \mathrm{mM})$ and $50 \mu \mathrm{l}$ of RNaseA $(1 \mathrm{mg} / \mathrm{ml})$. After $30 \mathrm{~min}$ cells were analyzed for DNA content using a FACS flow cytometer. Fluorescence from the PI-DNA complex was estimated on a minimum of 20000 cells per sample and analyzed with CellQuest Pro software.

TUNEL assay. Si-LEDGF- and scrambled Si-Control-transfected cells were seeded onto coverslips and incubated for $24 \mathrm{~h}$. TUNEL staining (in situ cell death detection kit, Roche Diagnostics $\mathrm{GmbH}$ ) and staining with 4',6-diamidino-2phenylindole dihydrochloride (DAPI) (Dojindo Laboratories, Kumamoto, Japan) were performed. The percentage of TUNEL-positive cells per total number of cells was counted from the number of DAPI-stained nuclei in six different fields of each slide for each group using the image analyzing software.

Wound-healing assay. Si-LEDGF-transfected and Si-Control-transfected cells or pEGFP-V or pEGFP-LEDGF-transfected cells were seeded into $60-\mathrm{mm}$ dishes at $1.5 \times 10^{6}$ cells. The confluent cell monolayer was scraped with a sterile pipette tip with a fixed diameter. For each dish, three-five wounds were made, and three sites of regular wounds were selected and marked. Wounded monolayers were then washed three times with PBS to remove cell debris. Cells were permitted to migrate into the area of clearing for $24 \mathrm{~h}$. Immediately after wounding and at the end of the experiment (after $24 \mathrm{~h}$ ), wounds were photographed and semiquantitative measurements of wounds were taken. A mean width was determined, and the average width of wound closure was calculated as described previously.

Cell invasion assay. Invasion assay was performed with Cytoselect TM 96-well cell invasion assay (Cell Biolabs, INC., San Diego, CA, USA) according to manufacturer's instructions. Briefly, around $2 \times 10^{6}$ cells per well of both SiControl and Si-LEDGF or pEGFP-V- or pEGFP-LEDGF-transfected cells were resuspended in serum-free MEM medium, and were seeded into the extracellular matrix layer, which had been previously rehydrated at room temperature for $1-2 \mathrm{~h}$. MEM media of $150 \mu$ l containing $10 \%$ fetal bovine serum was added to the lower chamber as chemo attractant. Cells were incubated for $24 \mathrm{~h}$ at $37^{\circ} \mathrm{C}$ in a $\mathrm{CO}_{2}$ incubator $\left(5 \% \mathrm{CO}_{2}\right)$. Invaded cells on the bottom of the insert membrane were dissociated from the membrane by incubation with cell detachment buffer and subsequently lysed and detected by CyQuant GR dye. The fluorescence was quantified with a fluorescence plate reader using a 480/535-nm filter set. Percent invasion index was calculated by normalizing the fluorescence reading of invaded cells with total cell fluorescence reading. Invaded cells on the membrane were photomicrographed under fluorescent microscope from each set of experiments, by fixing the membrane in methanol and then stained with CyQuant GR dye.

Statistical analysis. All the statistical analyses were done in Graphpad Prism software (La Jolla, CA, USA). Comparison between two groups were done with student $t$-test. Multiple comparisons were done by ANOVA. A $P$-value of $<0.01$ and $<0.001$ was defined as indicating a statistically significant difference.

\section{Conflict of Interest}

The authors declare no conflict of interest.

Acknowledgements. Grants provided by the National Eye Institute (NIH) (EY013394 and EY017613) (to DPS) and Research for Preventing Blindness (RPB) are gratefully acknowledged.

1. Singh DP, Fatma N, Kimura A, Chylack LT, Shinohara T. LEDGF binds to heat shock and stress-related element to activate the expression of stress-related genes. Biochemi Biophys Res Commun 2001; 283: 943-955.

2. Singh DP, Kimura A, Chylack LT Jr, Shinohara T. Lens epithelium-derived growth factor (LEDGF/p75) and p52 are derived from a single gene by alternative splicing. Gene 2000; 242: 265-273.

3. Sutherland HG, Newton K, Brownstein DG, Holmes MC, Kress C, Semple CA et al. Disruption of Ledgf/Psip1 Results in Perinatal Mortality and Homeotic Skeletal Transformations. Mol Cell Biol 2006; 26: 7201-7210.

4. Maurer-Stroh S, Dickens NJ, Hughes-Davies L, Kouzarides T, Eisenhaber F, Ponting CP. The Tudor domain 'Royal Family': Tudor, plant Agenet, Chromo, PWWP and MBT domains. Trends Biochem Sci 2003; 28: 69-74.

5. Stec I, Nagl SB, van Ommen GJ, den Dunnen JT. The PWWP domain: a potential proteinprotein interaction domain in nuclear proteins influencing differentiation? FEBS Lett 2000; 473: $1-5$.

6. $\mathrm{Ge} \mathrm{H}, \mathrm{Si} Y$, Roeder RG. Isolation of cDNAs encoding novel transcription coactivators p52 and $p 75$ reveals an alternate regulatory mechanism of transcriptional activation. EMBO J 1998; 17: 6723-6729.

7. Singh DP, Ohguro N, Chylack LT Jr, Shinohara T. Lens epithelium-derived growth factor: increased resistance to thermal and oxidative stresses. Invest Ophthalmol Vis Sci 1999; 40: $1444-1451$.

8. Maertens GN, Cherepanov P, Engelman A. Transcriptional co-activator p75 binds and tethers the Myc-interacting protein JPO2 to chromatin. J Cell Sci 2006; 119: 2563-2571.

9. Yokoyama A, Cleary ML. Menin critically links MLL proteins with LEDGF on cancerassociated target genes. Cancer Cell 2008; 14: 36-46. 
10. Bartholomeeusen K, Christ F, Hendrix J, Rain JC, Emiliani S, Benarous R et al. Lens epithelium-derived growth factor/p75 interacts with the transposase-derived DDE domain of PogZ. J Biol Chem 2009; 284: 11467-11477.

11. Hughes S, Jenkins V, Dar MJ, Engelman A, Cherepanov P. Transcriptional co-activator LEDGF interacts with Cdc7-activator of S-phase kinase (ASK) and stimulates its enzymatic activity. J Biol Chem 2010; 285: 541-554.

12. Fatma N, Singh DP, Shinohara T, Chylack LT. Transcriptional regulation of the antioxidant protein 2 gene, a thiol-specific antioxidant, by lens epithelium-derived growth factor to protect cells from oxidative stress. J Biol Chem 2001; 276: 48899-48907.

13. Sharma P, Fatma N, Kubo E, Shinohara T, Chylack LT Jr, Singh DP. Lens epitheliumderived growth factor relieves transforming growth factor-beta1-induced transcription repression of heat shock proteins in human lens epithelial cells. J Biol Chem 2003; 278 : 20037-20046.

14. Matsui $H$, Lin L-R, Singh DP, Shinohara T, Reddy VN. Lens epithelium-derived growth factor: increased survival and decreased DNA breakage of human RPE cells induced by oxidative stress. Invest Ophthalmol Vis Sci 2001; 42: 2935-2941.

15. Machida S, Chaudhry P, Shinohara T, Singh DP, Reddy VN, Chylack LT et al. Len epithelium-derived growth factor promotes photoreceptor survival in light-damaged and RCS rats. Invest Ophthalmol Vis Sci 2001; 42: 1087-1095.

16. Cohen B, Addadi Y, Sapoznik S, Meir G, Kalchenko V, Harmelin A et al. Transcriptiona regulation of vascular endothelial growth factor $C$ by oxidative and thermal stress is mediated by lens epithelium-derived growth factor/p75. Neoplasia 2009; 11: 921-933.

17. Sapoznik S, Cohen B, Tzuman Y, Meir G, Ben-Dor S, Harmelin A et al. Gonadotropinregulated lymphangiogenesis in ovarian cancer is mediated by LEDGF-induced expression of VEGF-C. Cancer Res 2009; 69: 9306-9314.

18. Daniels T, Zhang J, Gutierrez I, Elliot ML, Yamada B, Heeb MJ et al. Antinuclear autoantibodies in prostate cancer: immunity to LEDGF/p75, a survival protein highly expressed in prostate tumors and cleaved during apoptosis. Prostate 2005; 62: 14-26.

19. Sharma P, Singh DP, Fatma N, Chylack LT, Shinohara T. Activation of LEDGF gene by thermal- and oxidative-stresses. Biochem Biophys Res Commun 2000; 276 1320-1324.

20. Mehlen $P$, Schulze-Osthoff K, Arrigo AP. Small stress proteins as novel regulators of apoptosis. Heat shock protein 27 blocks Fas/APO-1- and staurosporine-induced cell death. J Biol Chem 1996; 271: 16510-16514.

21. Crowell JA, Steele VE, Fay JR. Targeting the AKT protein kinase for cance chemoprevention. Mol Cancer Ther 2007; 6: 2139-2148.

22. Hansen RK, Parra I, Lemieux P, Oesterreich S, Hilsenbeck SG, Fuqua SA. Hsp27 overexpression inhibits doxorubicin-induced apoptosis in human breast cancer cells. Breast Cancer Res Treat 1999; 56: 187-196.

23. Kim EH, Lee HJ, Lee DH, Bae S, Soh JW, Jeoung D et al. Inhibition of heat shock protein 27-mediated resistance to DNA damaging agents by a novel PKC delta-V5 heptapeptide. Cancer Res 2007; 67: 6333-6341.

24. Aloy MT, Hadchity E, Bionda C, Diaz-Latoud C, Claude L, Rousson R et al. Protective role of $\mathrm{Hsp} 27$ protein against gamma radiation-induced apoptosis and radiosensitization effects of Hsp27 gene silencing in different human tumor cells. Int J Radiat Oncol Biol Phys 2008; 70: $543-553$

25. Matsui Y, Hadaschik BA, Fazli L, Andersen RJ, Gleave ME, So Al. Intravesical combination treatment with antisense oligonucleotides targeting heat shock protein-27 and HTI-286 as a novel strategy for high-grade bladder cancer. Mol Cancer Ther 2009; 8: 2402-2411.
26. Cornford PA, Dodson AR, Parsons KF, Desmond AD, Woolfenden A, Fordham $\mathrm{M}$ et al. Heat shock protein expression independently predicts clinical outcome in prostate cancer. Cancer Res 2000; 60: 7099-7105.

27. Eisenmann KM, VanBrocklin MW, Staffend NA, Kitchen SM, Koo HM. Mitogen-activated protein kinase pathway-dependent tumor-specific survival signaling in melanoma cells through inactivation of the proapoptotic protein bad. Cancer Res 2003; 63: 8330-8337.

28. Miller H, Poon S, Hibbert B, Rayner K, Chen YX, O'Brien ER. Modulation of estrogen signaling by the novel interaction of heat shock protein 27 , a biomarker for atherosclerosis, and estrogen receptor beta: mechanistic insight into the vascular effects of estrogens. Arterioscler Thromb Vasc Biol 2005; 25: e10-e14.

29. Darnell JE. Transcription factors as targets for cancer therapy. Nat Rev Cancer 2002; 2: 740-749

30. Huang T-s, Myklebust L, Kjarland E, Gjertsen B, Pendino F, Bruserud O et al. LEDGF/p75 has increased expression in blasts from chemotherapy-resistant human acute myelogenic leukemia patients and protects leukemia cells from apoptosis in vitro. Mol Cancer 2007; 6: 31

31. Fire A, Xu S, Montgomery MK, Kostas SA, Driver SE, Mello CC. Potent and specific genetic interference by double-stranded RNA in Caenorhabditis elegans. Nature 1998; 391: 806-811.

32. Long XE, Gong ZH, Pan L, Zhong ZW, Le YP, Liu Q et al. Suppression of CDK2 expression by siRNA induces cell cycle arrest and cell proliferation inhibition in human cancer cells. BMB Rep 2010; 43: 291-296.

33. Song $\mathrm{H}$, Ethier SP, Dziubinski ML, Lin J. Stat3 modulates heat shock $27 \mathrm{kDa}$ protein expression in breast epithelial cells. Biochem Biophys Res Commun 2004; 314: 143-150.

34. Gibertzzz B, Eckelzzz B, Fasquellezzz L, Moulinzzz M, Bouhallierzzz F, Goninzzz V et al. Knock down of heat shock protein 27 (HspB1) induces degradation of several putative client proteins. PLOS ONE 2012; 7: e29719.

35. Pinthus JH, Bryskin I, Trachtenberg J, Lu JP, Singh G, Fridman E et al. Androgen induces adaptation to oxidative stress in prostate cancer: implications for treatment with radiation therapy. Neoplasia 2007; 9: 68-80.

36. Zoubeidi A, Zardan A, Wiedmann RM, Locke J, Beraldi E, Fazli L et al. Hsp27 promotes insulin-like growth factor-I survival signaling in prostate cancer via p90Rsk-dependent phosphorylation and inactivation of BAD. Cancer Res 2010; 70: 2307-2317.

37. Tyson JJ. Modeling the cell division cycle: cdc2 and cyclin interactions. Proc Nat Acad Sci 1991; 88: 7328-7332.

38. Fatma N, Singh P, Chhunchha B, Kubo E, Shinohara T, Bhargavan B et al. Deficiency of Prdx6 in lens epithelial cells induces ER stress-response-mediated impaired homeostasis and apoptosis. Am J Physiol Cell Physiol 2011; 301: C954-C967.

39. Takamura Y, Fatma N, Kubo E, Singh DP. Regulation of heavy subunit chain of gammaglutamylcysteine synthetase by tumor necrosis factor-alpha in lens epithelial cells: role of LEDGF/p75. Am J Physiol Cell Physiol 2006; 290: C554-C566.

Cell Death and Disease is an open-access journal published by Nature Publishing Group. This work is licensed under the Creative Commons Attribution-NonCommercial-No Derivative Works 3.0 Unported License. To view a copy of this license, visit http://creativecommons.org/licenses/by-nc-nd/3.0/ 